\title{
Demographic Transition and Industrial Revolution: A Macroeconomic Investigation
}

\author{
Michael Bar and Oksana Leukhina
}

December 2006

\begin{abstract}
All industrialized countries experienced a transition from high birth rates and stagnant standards of living to low birth rates and sustained growth in per capita income. What contributed to these transformations? Did economic and demographic changes transpire through common or distinct channels? We construct a general equilibrium model with endogenous fertility in order to quantitatively investigate the English case. We find that mortality decline significantly influences birth rates. Increased productivity has a negligible effect on birth rates but accounts for nearly all of the increase in per capita output, industrialization, urbanization, and the decline of land share in total income. The quantitative assessment of these two channels (young-age mortality and productivity) conducted in this paper sheds light on the relative importance of several theoretical mechanisms developed in this field.
\end{abstract}

Keywords: demographic transition, industrialization, mortality, technological progress JEL Codes: J10, O1, O4, E0 


\section{Introduction}

All industrialized countries have experienced a transition from stagnant standards of living to sustained growth in per capita income. Over the same period of time, resources reallocated from rural to non-rural production, land income share significantly declined, while labor income share increased. In each case, this economic transition concurred with the demographic transition from high to low birth and mortality rates. These key changes together constitute one of the major transformations of modern times.

What factors were responsible for these changes and to what extents? Did the economic and demographic changes transpire through common or distinct channels? To answer these questions and further understand the link between the economic and population dynamics, we construct a dynamic general equilibrium two-sector model with endogenous fertility. Within the framework of our model, parameterized to match key moments of 17th century England, we quantitatively assess the importance of two factors (channels) in shaping the demographic and economic transformation in England: changes in young-age mortality and technological progress. More precisely, we examine the model dynamics that result when changes in young-age mortality and total factor productivity (TFP) in the rural and non-rural sectors are stipulated to vary over time in accordance with historical data. ${ }^{1}$ It is important to note that we investigate the effects of empirical series of TFP and young-age mortality without asking what the underlying causes were for their behavior, and hence we refer to these effects as channels. For example, a finding that technological progress is quantitatively a major channel through which resource reallocation towards urban production transpired would not lead to the conclusion that changes in young-age mortality (or any force other than TFP) had no causal effect with regard to this phenomenon. Instead, this finding would merely suggest that if a given force contributed to resource reallocation, its influence must have been communicated predominantly though its effect on TFP.

We choose to focus on the effect of changes in young-age mortality and TFP because empirical evidence and related historical, demographic, and economic literature overwhelmingly link these factors to economic and demographic variables. ${ }^{2}$

Related work has provided a number of insightful dynamical systems capturing potentially very im-

\footnotetext{
${ }^{1}$ Three experiments are performed within the parameterized framework: (1) changing TFP growth rates while keeping young-age mortality at its initial level; (2) changing young-age mortality while keeping TFP growth rates at their initial values; (3) changing both simultaneously.

${ }^{2}$ See Section II.
} 
portant mechanisms. However, many of these point to drastically different causes behind the economic and demographic transformations. To give just a few examples, Greenwood and Seshadri (2000), Jones (2001), Kalemli-Ozcan (2002) and Soares (2005) each generates a drop in fertility and a take-off to a sustained growth regime through the acceleration of technological progress, institutional change, a decline in young-age mortality, and a decline in adult mortality, respectively. Thus, the relative importance of each such mechanism for the case of a particular country remains unclear.

Our quantitative findings help elucidate the relative importance of each of these mechanisms for the case of England. Our framework is general enough to allow for a number of existing models developed for the purpose of jointly studying growth and demographics to be mapped into it. For example, consider a model developed in Galor and Weil (2000). In that work, children's human capital is a function of the TFP growth rate and parental time investment in raising children. This function is chosen so as to satisfy several assumptions guaranteeing that parents respond to the acceleration of technological progress by having fewer, higher quality children. The growing stock of human capital then feeds back into higher technological progress. Although there is no mortality or physical capital in Galor and Weil (2000), their mechanism is manifested in our model through the exogenous technological change together with the rising cost of children. ${ }^{3}$ Similarly, mechanisms that emphasize the role of declining old-age mortality, such as in Soares (2005), are manifested in our model through the channels of extending the time endowment per adult household ${ }^{4}$ together with technological progress and the rising cost of children.

An advantage of using our framework for assessing the relative importance of different channels on population, output, resource allocation and factor income shares is that it allows a straightforward mapping to the data. We use standard functional forms and our choice of parameters is strictly guided by the observables. We do not make any assumptions regarding parameters to guarantee certain behavior or tell a particular story. (For example, the utility function parameters can be chosen to guarantee that birth rates fall as income rises.) Indeed, the time series used in the design of our experiments represent their actual historical estimates. Our framework also enables us to estimate TFP series in the rural and urban sectors using the available data on wages, land and capital rental rates, and the GDP deflator. This is in contrast, for example, to the agricultural good production function assumed in Greenwood and

\footnotetext{
${ }^{3}$ More precisely, any behavior of variables exhibited in Galor and Weil (2000) can be generated in our model with particular sequences of parameters representing TFP and the time cost of raising children.

${ }^{4}$ We do not explore the importance of this particular channel in this paper. In fact, what is needed is a framework of growth accounting in a model with endogenous population growth that allows to decompose economomic and demographic changes into all these channels: technological progress, young-age, adult-age, old-age mortality and the cost of raising children.
} 
Seshadri (2000), with skilled labor, unskilled labor, and capital as inputs, for which productivity changes would be difficult to measure with available data.

Thus, to reemphasize the main contribution of this paper, it provides a thorough quantitative assessment of the two commonly mentioned channels (young-age mortality and sector-specific technical progress) in shaping the economic and demographic transformations of England. It does so in a way that sheds light on relative importance of several of the proposed theoretical mechanisms in this field. Moreover, our framework allows us to study these channels in isolation. This is in contrast to models encompassing intricate collections of forces that cannot be tested in isolation without shutting down the entire mechanism.

Also significant is our study of transitional dynamics from one type of balanced growth path (BGP) towards another, triggered by mortality and TFP changes. We find that a great deal of insight is lost when focusing on comparative statics analysis alone, as, in general, the convergence from one BGP to another is lengthy and may involve non-monotone behavior. Finally, this work adds to the knowledge of economic development over long time scales, the importance of which is emphasized in Lucas (2002).

Our model has three important components. First, the final good can be produced using two different technologies, the Malthusian, which takes capital, labor, and land as inputs, and, the Solow, which employs capital and labor only. Because land is a fixed factor, it essentially introduces decreasing returns to scale to capital and labor in the Malthusian sector. We associate the Malthusian technology with rural production and the Solow technology with urban production. This two-technology framework allows us to investigate the implications of changes in young-age mortality and TFP regarding resource allocation to the two technologies. ${ }^{5}$ The second important component in the model is endogenous fertility. Parents place value on both the number of surviving children and their children's well-being ${ }^{6}$, and thus face a quantity-quality trade-off between having many children each with a small inheritance in the form of capital and land and having a few children with a larger inheritance. Finally, the time cost of raising a surviving child declines as more newborns survive, to reflect the idea that fewer newborns are needed to realize one surviving offspring.

How do changes in young-age mortality and TFP growth rates propagate in our model? To highlight a few effects here, we focus on the implications of these changes for birth rates and the level of

\footnotetext{
${ }^{5}$ In this paper we refer to the fraction of non-rural output in the total output as "the level of industrialization" and the fraction of labor employed by the non-rural sector in the total labor as "the level of urbanization."

${ }^{6}$ We use two specifications, one as in Barro and Becker (1989) and one as in Lucas (2002).
} 
industrialization.

The most direct effect of the decline in young-age morality is that fewer births are needed to realize the desired number of surviving children. Further, because parents must invest time into the raising of each child, declining young-age mortality lowers the time cost of surviving children, thus relaxing the budget constraint and allowing parents to optimally adjust the number and quality of their surviving offspring.

The transition to a more rapidly growing TFP and hence income may also alter fertility choices. On one hand, children are normal goods, and therefore, higher income growth induces higher fertility. On the other hand, rearing children takes time, and with a more rapidly growing TFP, the opportunity cost of raising children measured in terms of foregone wage earnings also grows faster, and this results in a dampening of fertility. In addition, with more rapidly growing incomes, parents choose to have higher quality children, which further increases the cost of rearing children.

Interestingly, when separate experiments are conducted within the parameterized model to independently determine the implications of technological progress and the change in young-age mortality, it is found that each generates full resource reallocation towards the urban sector. As the Solow TFP begins to grow more rapidly than the Malthusian TFP, the Solow sector attracts an increasingly higher proportion of resources. The result that falling young-age mortality causes an increase in the level of industrialization is less intuitive. However, this can be understood by first noting that as the probability of survival increases, the time cost of raising a surviving child declines, which leads to an augmentation of the aggregate labor supply. This, in turn, results in a relative expansion of the output in the Solow sector, which uses labor intensively. This is the type of logic employed in the Rybczynski Theorem. Such possible effect of young-age mortality on the level of industrialization as described here has gone unnoticed by related works.

In this work, we find that the decline in young-age mortality accounts for $59 \%$ of the fall in the crude birth rate $(\mathrm{CBR})^{7}$, while changes in productivity account for $73 \%$ of the increase in GDP per capita and for over $90 \%$ of the movement in factor income shares for the period 1650-1950 in England. Although both changes generate a transition from Malthus to Solow, only changes in the TFP growth do so in a manner consistent with empirical observations, driving the share of the Malthusian output from approximately $67 \%$ to nearly zero in the period from 1600 to 2000 . Changes in young-age mortality lead to a much

\footnotetext{
${ }^{7}$ The crude birth rate (crude death rate (CDR)) is the number of births (deaths) in a given year per 1000 people.
} 
slower transition, according to which even in 2400, the Malthusian output would represent as much as 10 percent of the total output. Our finding that changes in TFP account for long-term trends in the observed patterns of factor income shares can be contributed to resource reallocation between sectors with different but constant factor elasticities.

Interestingly, we find that changes in productivity are quantitatively insignificant in accounting for the observed patterns in fertility behavior, while mortality changes are quantitatively relevant only to population dynamics. This finding does not rule out the possibility of important interactions between changes in mortality and productivity, nor the existence of some other force responsible for both of these changes. Instead, it suggests only that the quantitatively relevant channels through which the demographic and economic transformations transpired are distinct.

\section{Related Literature}

Let us briefly discuss related works. There are several theoretical and quantitative studies that focus on the role of mortality in driving the demographic and/or economic transition. Among these are Ehrlich and Lui (1991), Wolpin (1997), Eckstein et al. (1999), Kalemli-Ozcan et al. (2000), Kalemli-Ozcan (2002), Lagerloff (2003), Doepke (2005), Soares (2005), Tamura (2006). ${ }^{8}$ All of these works employ a quantity-quality trade-off. Ehrlich and Lui (1991), Kalemli-Ozcan (2002), Lagerloff (2003), Soares (2005) and Tamura (2006) explicitly model human capital accumulation and assume increasing returns to scale to parents' human capital and time spent with children in production of children's human capital. ${ }^{9}$ Because the production of the surviving children's human capital requires a quantity of parents' time that is proportional to their fertility, a drop in young-age mortality raises the return to human capital investment. The necessary parametric restrictions are then made to ensure a transition to a sustained growth regime through substitution of quality for quantity. ${ }^{10} \mathrm{~A}$ few of these studies, in particular, Ehrlich and Lui (1991), Kalemli-Ozcan (2002), Lagerloff (2003), Soares (2005) and Tamura (2006) conclude that a decline in child mortality results in a significant reduction of the number of surviving children and pulls the economy onto a sustained growth path.

\footnotetext{
${ }^{8}$ Boldrin and Jones (2002) also explores the role of mortality but in a framework that reverses the direction of altruism. Empirical results pointing to mortality as one of the most important determinants of fertility and/or the onset and speed of its decline are reported in Woods (1987), Bos and Bulatao (1990), Shultz (1997) and Mason (1997a), among others.

${ }^{9}$ Doepke (2005) also studies a setup with human capital accumulation. However, he assumes that children's human capital is a decreasing returns to scale function of only parents' time spent with children.

${ }^{10}$ Soares (2005) and Kalemli-Ozcan et al. (2005) explore the effect of changes in adult mortality on human capital accumulation.
} 
The view that technological progress governs fertility choices and/or the process of development is also common. ${ }^{11}$ (See Becker and Lewis (1973), Becker (1981), Hotz et al. (1997), Galor and Weil (2000), Fernandez-Villaverde (2001), Greenwood and Seshadri (2002), Hansen and Prescott (2003).) In fact, our findings are qualitatively consistent with this view, as they imply that changes in TFP growth trigger convergence to a sustained growth regime characterized by lower fertility. Interestingly, we find the effect of technological progress on birth rates to be small.

With regard to the method of modeling production, our work is closely related to Hansen and Prescott (2003). However, in contrast to Hansen and Prescott (2003), in which population growth is postulated to be a function of per capita consumption, we explicitly model fertility choice and young-age mortality. Fernandez-Villaverde (2001) uses a parameterized framework in which unskilled labor and capital are substitutes while skilled labor and capital are complements. Capital-specific technological change that matches the fall in the relative price of capital equipment during the years of falling birth rates, 1875-1920, is introduced into the model and found important in accounting for the observed patterns of fertility and per capita income in England. However, the empirical fact that after 1920 the relative price of capital and capital equipment reverts its downward trend, although there is no reversion of the trend in fertility, is difficult to reconcile with this finding.

Greenwood and Seshadri (2000) uses a two-sector model with exogenous technological progress and endogenous fertility to study the case of the U.S. The preference parameters are chosen such that as incomes increase the demand for the agricultural good relative to the manufacturing good declines. Because unskilled labor is not used in the production of the manufacturing good, parents substitute quality for quantity. Galor and Weil (2000) presents a theoretical model with explicit human capital accumulation, endogenous technological change and fertility already discussed. ${ }^{12}$ By contrast, we avoid heterogeneity in skills and human capital considerations. This greatly reduces the difficulty of mapping observables into our model. Further, Greenwood and Seshadri (2000) and Galor and Weil (2000) abstract from young-age mortality; hence, surviving children and fertility are represented by the same time series in these models, in sharp contrast with the data.

The remainder of the paper is organized as follows. In Section III we summarize the historical data

\footnotetext{
${ }^{11}$ We only highlight work directly related to our focus on technological change and young-age mortality. It should be noted that there are several studies investigating other channels. Doepke (2004), for example, studies the effect of policies such as education subsidies and child-labor laws, while Becker et al. (1999) and Boucekkine et al. (2005) focus on population density.

${ }^{12}$ Lagerlof (2003) performs a quantitative test of this model.
} 
for England. In Section IV we set up the model and discuss its equilibrium properties. The model's calibration and estimation of TFP time series are presented in Section V. The main results are reported in Section VI. We present a sensitivity analysis in Section VII and conclude in Section VIII.

\section{Motivating Facts about England}

We chose to focus on England because its data are most complete. ${ }^{13}$ Floud and Johnson (2004) and Chesnais (1992) describe England during this period. Lee (2006) and Galor (2005) provide general accounts of the demographic change and facts concerning development.

Figure 1 displays the natural log of the real GDP per capita index. ${ }^{14}$ After remaining stagnant for centuries, real GDP per capita took off in the beginning of the 19th century. This period is also characterized by a large-scale shift of the population from the rural sector to the urban sector. As depicted in Figures 2 and 3, the share of the urban GDP rose from around 30\% in the 1550s to roughly $98 \%$ in the 1990s, while the share of employment in non-rural production increased from around $40 \%$ to 98\%. ${ }^{15}$ Further, the land income share fell from as much as $30 \%$ at the outset of the 17th century to nearly $0 \%$ today (Figure 4 ).

The dramatic economic transformation described above was accompanied by remarkable demographic changes (Figure 5). ${ }^{16}$ Before the mid 18th century, both birth and death rates remained high, with the average population growth in the first half of the 18th century remaining low (approximately $0.4 \%$ per year.) The decrease in the CDR beginning in the second half of the 18th century was due mainly to declining adult mortality. Sustained decline of the mortality rates for the age groups 5-10, 10-15, and 15-25 began in the mid 19th century, while that for the age group 0-5 began three decades later (Wrigley et al. (1997)). Major factors behind the decline in mortality were the sanitary revolution, which reduced fatalities due to water-borne and food-borne disease and advances in medical science, most notably, the discovery of the benefits of pasteurization, hospitalization, and small pox vaccination.

A sustained fall in birth rates, driven by a fall in marital fertility, occurred from 1870 to 1930 , after which both birth and death rates stabilized at their current low levels. Previous changes in birth rates resulted from changes in the timing and prevalence of marriage (Floud and Johnson (2004) and Wilson

\footnotetext{
${ }^{13}$ All data sources used in this paper are listed in the appendix.

${ }^{14}$ Data sources for this figure are Clark (2001a) for 1560-1860 and Maddison (1995) for 1850-1992.

${ }^{15}$ Data for the level of industrialization and urbanization up to 1860 are taken from Clark (2001a, 2002); the time series are continued using Maddison's data (1995).

${ }^{16}$ Data for CBR and CDR are taken from Wrigley et al. (1997) up to 1871 and continued using the data in Mitchell (1978).
} 
and Woods (1991)). The general fertility rate (GFR), ${ }^{17}$ a measure less sensitive to the age structure of the population than CBR, exhibited similar behavior (Figure 13). Although the fall in birth rates lagged behind the onset of the fall in death rates, it coincided with the fall in young-age mortality (Figure 6). ${ }^{18}$ Note that the lag between the drop in CDR and the drop in CBR resulted in a hump-shaped population growth rate.

Figure 7 plots our own TFP estimates. The rural TFP exhibited a somewhat higher growth than the non-rural TFP until the second half of the 18th century, when the growth of the urban TFP sharply increased surpassing that of the rural TFP. Around 1800, the growth of the rural TFP caught up slightly. This short-lived trend marks a small-scale agricultural revolution subsequent to the industrial revolution.

\section{Model}

\section{A. Environment}

\section{Technology and firms}

Firms are endowed with one of two possible technologies to be used in production of the consumption good. The Malthusian technology that requires capital, labor, and land as inputs is given the subscript "1," and it is associated with production taking place in the rural sector. The Solow technology that employs capital and labor as inputs is given the subscipt "2," and it is associated with production taking place in the cities. Both technologies exhibit constant returns to scale, which allows us to assume two aggregate competitive firms (sectors). Output production of these firms is described by $Y_{1 t}=$ $A_{1 t} K_{1 t}^{\phi} L_{1 t}^{\mu} \Lambda_{t}^{1-\phi-\mu}$ and $Y_{2 t}=A_{2 t} K_{2 t}^{\theta} L_{2 t}^{1-\theta}$, where $K_{j}$ and $L_{j}$ denote the capital and labor employed by technology $j \in\{1,2\}$, and $\Lambda_{t}$ denotes the land input. Exogenous technological change augments TFP in both technologies, so that $A_{j t}=A_{j 0} \prod_{\tau=0}^{t-1} \gamma_{j \tau}, j \in\{1,2\}$. Letting $w_{t}, r_{t}$, and $\rho_{t}$ denote the real wage, capital rental rate, and land rental price at time $t$, we can describe profit maximization by

$$
\begin{aligned}
& \max _{K_{1 t}, L_{1 t}, \Lambda_{t}} A_{1 t} K_{1 t}^{\phi} L_{1 t}^{\mu} \Lambda_{t}^{1-\phi-\mu}-w_{t} L_{1 t}-r_{t} K_{1 t}-\rho_{t} \Lambda_{t}, \\
& \max _{K_{2 t}, L_{2 t}} A_{2 t} K_{2 t}^{\theta} L_{2 t}^{1-\theta}-w_{t} L_{2 t}-r_{t} K_{2 t} .
\end{aligned}
$$

Preferences, households and dynasties ${ }^{19}$

\footnotetext{
${ }^{17}$ The general fertility rate is the number of births in a given year per 1000 females of ages 15-44.

${ }^{18}$ The probability of surviving to age 25 is calculated from age-specific mortality rates taken from Wrigley et al. (1997) and the Human Mortality Database.

${ }^{19}$ See Bar and Leukhina (2006) for a more rigorous description of this environment.
} 
There is a measure 1 of identical dynasties, each populated by $N_{t}$ households at time $t$. Households live for two periods, childhood and adulthood. An adult household derives utility from its own consumption $\left(c_{t}\right)$, the number of its surviving children $\left(n_{t}\right)$, and its children's average utility according to $U_{t}=$ $\alpha \log c_{t}+(1-\alpha) \log n_{t}+\beta U_{t+1}$, where $\alpha, \beta \in(0,1)$. This utility function, also used in Lucas (2002), is increasing and concave in the number of children, like the utility used in Barro and Becker (1989), $U_{t}=c_{t}^{\sigma}+\beta n_{t}^{1-\varepsilon} U_{t+1}$. In the appendix, we prove that these preferences are equivalent if $\sigma \rightarrow 0$ and $\frac{1-\varepsilon-\sigma}{\sigma}=\frac{1-\alpha-\beta}{\alpha \beta}$. We also explore the Barro and Becker utility in the sensitivity section.

A fraction $\pi_{t}$ of children born $\left(f_{t}\right)$ survive to adulthood, ${ }^{20}$ and thus $f_{t}=\frac{n_{t}}{\pi_{t}}$ newborns are needed to realize $n_{t}$ surviving offspring. A household must spend a fraction $a$ of its time with each born child and an additional fraction $b$ with each child who lives to adulthood. ${ }^{21}$ Allowing two parameters govern the cost of raising children enables us to capture the young-age mortality profile. For example, a high value of $b$ relative to $a$ captures the empirical observation that children not surviving to adulthood tend to die very early in life. We will return to this discussion when calibrating the model. The total time spent raising children is hence given by $a f_{t}+b n_{t}=\left(\frac{a}{\pi_{t}}+b\right) n_{t}$. We let $q_{t} \equiv \frac{a}{\pi_{t}}+b$ denote the net time cost per surviving child. Observe that $q_{t}$ is a decreasing function of $\pi_{t}$. Intuitively, as more newborn children survive to adulthood, fewer newborns are needed to realize one surviving offspring and hence less time is spent rearing non-survivors.

An adult household rents its land holdings $\left(\lambda_{t}\right)$ and capital $\left(k_{t}\right)$, and devotes all time not spent raising children to work $\left(l_{t}=1-q_{t} n_{t}\right)$. Given $\left\{w_{t}, r_{t}, \rho_{t}, q_{t}\right\}_{t=0}^{\infty}$, households choose consumption, the number of surviving children, the amount of capital $\left(k_{t+1}\right)$ to pass on to each surviving child, and divide their land holdings equally among its descendants. The problem faced by an adult household is thus given by

$$
\begin{aligned}
U_{t}\left(k_{t}, \lambda_{t}\right) & =\max _{c_{t}, n_{t}, \lambda_{t+1}, k_{t+1} \geq 0} \alpha \log c_{t}+(1-\alpha) \log n_{t}+\beta U_{t+1}\left(k_{t+1}, \lambda_{t+1}\right) \\
\text { subject to } c_{t}+k_{t+1} n_{t} & =\left(1-q_{t} n_{t}\right) w_{t}+\left(r_{t}+1-\delta\right) k_{t}+\rho_{t} \lambda_{t} \\
\lambda_{t+1} & =\frac{\lambda_{t}}{n_{t}} .
\end{aligned}
$$

It is common to assume that the conjecture about $U_{t+1}\left(k_{t+1}, \lambda_{t+1}\right)$ formed by a time $t$ adult household

\footnotetext{
${ }^{20}$ There is no uncertainty in the survival of newborns' (as in Sah (1991) or Kalemli-Ozcan (2002)) that would give rise to precautionary motives for having children.

${ }^{21}$ If the cost of raising children were to be paid in terms of the final good, the results would not change. In that case, for the existence of a balanced growth path along which per capita variables grow at constant rates, we would need to assume that the goods cost grows in proportion to income.
} 
must correspond to the actual level of its children's utility resulting from their optimal response to inheriting $\left(k_{t+1}, \lambda_{t+1}\right)$. In other words, we focus on subgame perfect equilibria of an infinite horizon dynastic game, in which at each time, current adults solve the above problem. As in Golosov, Jones, Tertilt (2006), it can be shown that the subgame perfect equilibrium outcome of such game is unique ${ }^{22}$ and coincides with the unique solution to the dynastic problem (DP) below ${ }^{23}$, where the objective function obtains applying recursive substitution to household utility. This allows us to work with a much easier to handle DP problem. Given $\left\{w_{t}, r_{t}, \rho_{t}, q_{t}\right\}_{t=0}^{\infty}$, the dynastic planner (or the original household) solves

$$
\begin{gathered}
\max _{\left\{c_{t}, n_{t}, \lambda_{t+1}, k_{t+1}\right\}_{t \geq 0}} \sum_{t=0}^{\infty} \beta^{t}\left(\alpha \log c_{t}+(1-\alpha) \log n_{t}\right) \\
\text { subject to } c_{t}+k_{t+1} n_{t}=\left(1-q_{t} n_{t}\right) w_{t}+\left(r_{t}+1-\delta\right) k_{t}+\rho_{t} \lambda_{t}, \forall t \\
\lambda_{t+1}=\frac{\lambda_{t}}{n_{t}}, c_{t}, n_{t}, k_{t+1} \geq 0, k_{0}, \lambda_{0} \text { given }
\end{gathered}
$$

\section{Population dynamics and market clearing}

The number of adult households evolves according to $N_{t+1}=n_{t} N_{t}$. We use upper case letters to denote aggregate quantities: $C_{t} \equiv c_{t} N_{t}, K_{t} \equiv k_{t} N_{t}, K_{1 t} \equiv k_{1 t} N_{t}, K_{2 t} \equiv k_{2 t} N_{t}, L_{t}=l_{t} N_{t}, L_{1 t} \equiv l_{1 t} N_{t}$, $L_{2 t} \equiv l_{2 t} N_{t}$. The market clearing conditions in the final goods, capital, labor, and land markets are given by

$$
\begin{aligned}
C_{t}+K_{t+1} & =A_{1 t} K_{1 t}^{\phi} L_{1 t}^{\mu} \Lambda_{t}^{1-\phi-\mu}+A_{2 t} K_{2 t}^{\theta} L_{2 t}^{1-\theta}+(1-\delta) K_{t} \\
K_{1 t}+K_{2 t} & =K_{t} \\
L_{1 t}+L_{2 t} & =\left(1-q_{t} n_{t}\right) N_{t}, \\
\Lambda_{t} & =\Lambda .
\end{aligned}
$$

\section{B. Equilibrium}

Definition 1 A competitive equilibrium, for given parameter values, initial conditions $\left(k_{0}, N_{0}\right)$ and exogenous sequences $\left\{\gamma_{1 t}, \gamma_{2 t}, \pi_{t}\right\}_{t=0}^{\infty}$, consists of the allocations $\left\{c_{t}, n_{t}, \lambda_{t}, k_{t+1}, k_{1 t}, k_{2 t}, l_{t}, l_{1 t}, l_{2 t}, N_{t+1}\right\}_{t=0}^{\infty}$ and prices $\left\{w_{t}, r_{t}, \rho_{t}\right\}_{t=0}^{\infty}$ such that firms' and dynastic maximization problems are solved, and all markets clear.

\footnotetext{
${ }^{22}$ The only equilibria considered are those that are limits of equilibria of the finite horizon truncations of this infinite horizon game.

${ }^{23}$ Bar and Leukhina (2006) prove uniqueness of the solution to DP.
} 


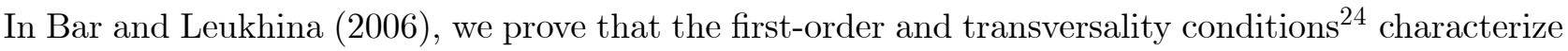
the solution to DP. It is instructive to review the intuition behind the first-order conditions written in dynastic aggregates,

$$
\begin{aligned}
\frac{C_{t+1}}{C_{t}} & =\beta\left(r_{t+1}+1-\delta\right) \\
\frac{(1-\alpha-\beta) C_{t}}{\alpha N_{t+1}} & =q_{t} w_{t}-\frac{w_{t+1}}{r_{t+1}+1-\delta}
\end{aligned}
$$

Equation (1) is a standard Euler equation that describes the intertemporal trade-off in aggregate consumption. Condition (2) represents the intratemporal trade-off between consumption and surviving children. The marginal rate of substitution between children and consumption is given by their relative price, that is, forgone parental wages due to the time cost of raising children less the present value of the child's earnings at $t+1$.

Due to decreasing returns to scale in capital and labor, the marginal products of the inputs in the Malthusian technology become very large when its capital and labor inputs approach zero. This guarantees that the Malthusian technology is always employed ${ }^{25}$, and factor prices are determined by

$$
\begin{aligned}
r_{t} & =\phi A_{1 t} K_{1 t}^{\phi-1} L_{1 t}^{\mu} \Lambda^{1-\phi-\mu}, \\
w_{t} & =\mu A_{1 t} K_{1 t}^{\phi} L_{1 t}^{\mu-1} \Lambda^{1-\phi-\mu}, \\
\rho_{t} & =(1-\phi-\mu) A_{1 t} K_{1 t}^{\phi} L_{1 t}^{\mu} \Lambda^{-\phi-\mu} .
\end{aligned}
$$

It is profitable to operate the Solow technology as long as $1 \geq \frac{1}{A_{2 t}}\left(\frac{\phi A_{1 t} K_{t}^{\phi-1} L_{t}^{\mu} \Lambda^{1-\phi-\mu}}{\theta}\right)^{\theta}\left(\frac{\mu A_{1 t} K_{t}^{\phi} L_{t}^{\mu-1} \Lambda^{1-\phi-\mu}}{1-\theta}\right)^{1-\theta}$, that is, as long as its unit cost computed when all resources are employed in the Malthusian sector does not exceed 1 , in which case factor prices equalize across the two sectors: $\phi A_{1} K_{1}^{\phi-1} L_{1}^{\mu} \Lambda^{1-\phi-\mu}=$ $\theta A_{2}\left(K-K_{1}\right)^{\theta-1}\left(L-L_{1}\right)^{1-\theta}$ and $\mu A_{1} K_{1}^{\phi} L_{1}^{\mu-1} \Lambda^{1-\phi-\mu}=(1-\theta) A_{2}\left(K-K_{1}\right)^{\theta}\left(L-L_{1}\right)^{-\theta}$.

\section{Limiting Behavior of Equilibrium Time Paths}

The behavior of equilibrium allocations depends on the choice of the parameters and initial conditions. We can identify three possible types of limiting behavior of equilibrium time paths, characterized by the properties that (1) the ratio of the output in the Solow sector to that in the Malthusian sector converges

\footnotetext{
${ }^{24}$ The transversality conditiona are given by $\lim _{t \rightarrow \infty} \beta^{t} \frac{\alpha\left(r_{t}+1-\delta\right)}{\left(N_{t}-q N_{t+1}\right) w_{t}+\left(r_{t}+1-\delta\right) K_{t}+\rho_{t} \Lambda-K_{t+1}} \quad K_{t} \quad=\quad 0 \quad$ and $\lim _{t \rightarrow \infty} \beta^{t} \frac{\alpha w_{t}}{\left(N_{t}-q N_{t+1}\right) w_{t}+\left(r_{t}+1-\delta\right) K_{t}+\rho_{t} \Lambda-K_{t+1}} N_{t}=0$

${ }^{25}$ Formal derivations of optimal resource allocation given $K_{t}$ and $L_{t}$ are given in Bar and Leukhina (2006).
} 
to a finite constant, (2) the level of output in the Solow sector converges to 0, (3) the ratio of the output in the Malthusian sector to that of the Solow sector converges to 0. We refer to these types of limiting behavior of equilibrium time paths as convergence to the Malthus-Solow balanced growth path (BGP), Malthus BGP, and Solow BGP, respectively. ${ }^{26}$

A detailed discussion of how parameter values and initial conditions affect the limiting behavior of equilibrium time paths, formulated in terms of propositions and proofs, is presented in the Supplemental Notes. It is, however, useful to point out here that along a Malthus-Solow BGP, both population growth $(n)$ and per capita output growth $(\gamma)$ are determined by the TFP growth rates in the two sectors: ${ }^{27}$

$$
\gamma=\gamma_{2}^{\frac{1}{1-\theta}}, n=\left(\gamma_{1} \gamma_{2}^{-\frac{1-\phi}{1-\theta}}\right)^{\frac{1}{1-\phi-\mu}}
$$

The growth rate of per capita output is an increasing function of the Solow TFP growth rate, while population growth increases in the Malthusian TFP growth rate and decreases in the Solow TFP growth rate. Interestingly, the time cost of raising children does not enter these two equations, and therefore a rise in $\pi$ would result in a proportional reduction of fertility $(n=\pi f)$. For this class of simulations, we found that during the transition from the original to a new BGP, population growth exhibits a hump. Therefore, from this statics exercise, it cannot be concluded that mortality changes do not affect population growth. Moreover, this analysis is valid only as long as the new value of $\pi$ does not alter the type of limiting behavior of equilibrium paths, i.e., as long as it does not preclude convergence to a new Malthus-Solow BGP. In fact, in each of the main experiments, we find a switch to a Solow BGP.

The growth rate of per capita output on a Solow BGP is also given by $\gamma=\gamma_{2}^{\frac{1}{1-\theta}}$. However, there is no explicit analytical solution for the growth rate of per capita output on a Malthus BGP ${ }^{28}$ nor for the growth rates of population along a Malthus BGP and a Solow BGP. The comparative statics results show that for both of these BGP types, an increase in the TFP growth rate leads to a decline in the population growth rate and an increase in the per capita output growth rate. For a Malthus BGP, an increase in the probability of survival has the opposite effect. For a Solow BGP, an increase in the survival probability leads to an increase in the population growth, but it does not affect the growth rate of per capita output.

\footnotetext{
${ }^{26}$ The existence of three types of limiting behavior here contrasts with the situation studied in Hansen and Prescott (2003). In that work, as long as the growth rate of the Solow TFP is positive, all equilibria exhibit convergence to a Solow BGP.

${ }^{27}$ This result is due to the constancy of the interest rate along a Malthus-Solow BGP and the equality of the marginal products of capital in the two sectors. Hence, it is robust with respect to the choice of the utility function.

${ }^{28}$ Equations describing equiliubrium behavior for different BGP types are derived in the Supplemental Notes.
} 


\section{Calibration and TFP estimation}

One objective is to calibrate the model parameters so as to match certain key data moments characterizing the English economy at the outset of the 17th century. Because per capita output growth, birth rates, factor shares in total income, young-age mortality, levels of urbanization and industrialization exhibited no trend during the period 1580-1650, we mapped the data moments into the parameters under the assumption that the English economy was on a Malthus-Solow BGP. Another objective is to estimate the time series of TFP in the rural and non-rural sectors. Because there are no data on time series of inputs and outputs for the two sectors, which are necessary for standard growth accounting, we implemented the dual approach of TFP estimation. This approach employs the assumption of profitmaximization and requires time series data on wages in the two sectors, land rental prices, capital rental rates, and the GDP deflator. The procedure we used for TFP estimation is intertwined with calibration, and for this reason we describe both of them in this section.

We chose each time period to represent 25 years. To be calibrated are the Malthusian parameters, $A_{10}, \gamma_{1}, \phi$ and $\mu$, the Solow parameters, $A_{20}, \gamma_{2}$ and $\theta$, the preference parameters, $\alpha$ and $\beta$, the cost of children parameters, $a, b$ and $\pi$, and the remaining parameters, $\Lambda$ and $\delta$.

Land is a fixed factor whose value we normalized to 1 . Since $A_{10}$ and $\Lambda$ always appear as a product $\left(A_{10} \Lambda^{1-\phi-\mu}\right)$, we are allowed a second degree of normalization, and we set $A_{10}=100$. For simplicity, we also set $A_{20}=100$, as we lack a criterion for making a more meaningful choice. ${ }^{29}$ Thus, we have 11 parameters left to calibrate. In order to pin them down, we rewrite the balanced growth path equations in terms of moments and parameters only, and then solve for the model parameters using the 11 pieces of information presented in Table $1.30,31$

Note that we do not aim to match per capita output growth and population growth in our model because, although stationary, these moments are quite volatile near the beginning of the 17th century. We do, however, compare these moments to their counterparts predicted by the calibrated model. Historical estimates of the annual depreciation rate range from 2.5\% (Clark 2002) to over 15\% (Allen 1982). We set $\delta=0.723$ to realize $5 \%$ annual depreciation. The probability of surviving to age 25 around 1600 was roughly constant at approximately 67\%. (Wrigley at al. (1997)). Hence, $\pi$ is also pinned down directly

\footnotetext{
${ }^{29}$ The choice of value for $A_{20}$ affects the magnitude of level variables, such as output or population size. Because we study growth rates and fractions of level variables, our results are insensitive to this choice.

${ }^{30}$ For a more technical description of the calibration process, which consists of solving this system of linear equations, see the Supplemental Notes.

${ }^{31}$ The numbers in parenthesis in the table and the rest of the paper represent annual rates.
} 
Table 1: England Around 1600: Data Moments Used for Calibration

\begin{tabular}{|l|l|}
\hline Data Moment & Description \\
\hline \hline$\delta=0.723(0.05)$ & Depreciation \\
$\pi=0.67$ & Probability of survival to 25 \\
$\frac{l_{1}}{l}=0.6$ & Fraction of rural labor in total labor \\
$\frac{y 1}{y}=0.67$ & Fraction of rural output in total output \\
$\frac{r k}{y}=0.16$ & Capital share in total income \\
$\frac{w l}{y}=0.6$ & Labor share in total income \\
$r+1-\delta=2.666(1.04)$ & Interest rate \\
$q n=0.42$ & Fraction of time spent with children (or not working) \\
$\frac{a+b}{a}=4$ & Time cost of a surviving child / that of a non-surviving child \\
$\gamma_{1,1600}=1.042(1.0016)$ & Growth of rural TFP around 1600 \\
$\gamma_{2,1600}=1.006(1.00025)$ & Growth of non-rural TFP around 1600 \\
\hline
\end{tabular}

by its data counterpart.

Clark (2001a) provides the labor and capital shares of the total output produced in England, as well as the relative levels of employment and output in the two sectors. The interest rate is taken from Clark (2001b). The fraction of time spent raising children $(q n)$ is set to 0.42 . There is no obvious way to infer qn from the data, but a simple example may be illustrative. For a person with 100 hours of time endowment per week, of which he works 40 hours, rests 30 hours and spends 30 hours with children, we would infer $q n=\frac{30}{30+40} \cong .429$, because there is no leisure in our model. Recall that $a$ is the fraction of time spent on each newborn child, while $b$ represents the additional time cost incurred when a child lives to become an adult. We set $\frac{a+b}{a}=4$, using the data on age-specific mortality and the assumption that the instantaneous cost function of raising a child is a decreasing linear function of the child's age. ${ }^{32}$ The sensitivity of the results to the choice of $\delta, q n$, and $\frac{a+b}{a}$ is addressed in Section VI. Our method for obtaining $\gamma_{1,1600}$ and $\gamma_{2,1600}$ is described below.

\section{Calibrating $\phi, \mu, \theta$}

We determine the labor share $\mu=0.537$ of the Malthusian technology using $\frac{y_{1}}{y}, \frac{l_{1}}{l}, \frac{w l}{y}$ and the equilibrium property that wages equal the marginal product of labor in the Malthusian sector, $w \frac{l}{y}=$ $\left(\frac{\mu y_{1}}{l_{1}}\right) \frac{l}{y}$. With $\mu$ known, we pin down the capital share of the Solow technology, $\theta$, by using $\frac{y_{1}}{y}, \frac{w l}{y}$, and the equality of the total labor income and the sum of incomes paid to labor in the two sectors, $\mu \frac{y_{1}}{y}+(1-\theta) \frac{y_{2}}{y}=\frac{w l}{y}$. This yields $\theta=0.273$. Similarly, the capital share of the Malthusian technology, $\phi$, is determined by $\frac{y_{1}}{y}, \frac{r k}{y}$, and the equality of the total income paid to capital and the sum of rental

\footnotetext{
${ }^{32}$ See the appendix for a more detailed explanation of how we arrive at this quantity.
} 
incomes paid to capital in each sector, $\phi \frac{y_{1}}{y}+\theta \frac{y_{1}}{y}=\frac{r k}{y}$. This gives $\phi=0.104$.

Calibrating $\gamma_{1}$ and $\gamma_{2}$ and estimating TFP time series

We next explain how $\gamma_{1,1600}$ and $\gamma_{2,1600}$ are obtained. We first estimate TFP time series for each sector during 1585-1915. ${ }^{33}$ Then, for each of these series we fit a trend consisting of two parts, each characterized by a constant growth rate. The growth rates characterizing the first part of the TFP trends in the two sectors are denoted by $\gamma_{1,1600}$ and $\gamma_{2,1600}$. In order to estimate the TFP time series, we use the inferred factor income shares in the two sectors, $\phi, \mu$ and $\theta$.

From profit maximization of the firms, we derive

$$
\begin{aligned}
& A_{1 t}=\left(\frac{r_{t}}{\phi}\right)^{\phi}\left(\frac{w_{1 t}}{\mu}\right)^{\mu}\left(\frac{\rho_{t}}{1-\phi-\mu}\right)^{1-\phi-\mu} \\
& A_{2 t}=\left(\frac{r_{t}}{\theta}\right)^{\theta}\left(\frac{w_{2 t}}{1-\theta}\right)^{1-\theta}
\end{aligned}
$$

where $r_{t}(\%)$ is the rental rate on capital, $w_{t}$ is the real wage measured in units of the final good per unit of labor, and $\rho_{t}$ is the land rental price measured in units of the final good per acre. Since Clark only provides the time series of $r_{t}(\%)$, nominal wages $\omega_{1 t}$ and $\omega_{2 t}(£), \tilde{\rho}_{t}$ (\% return on land rent), $P_{\Lambda t}$ (price of land in $£ /$ acre), and the GDP deflator $P_{t}$, we infer the real wages $w_{i t}$ and the real land rental price $\rho_{t}$ using $w_{i t}=\frac{\omega_{i t}}{P_{t}}$ and $\rho_{t}=\frac{\tilde{\rho}_{t} P_{\Lambda t}}{P_{t}}$.

Figure 7 displays these time series together with their trends. To see how a constant growth trend with a regime switch is fitted to a given series, let $x_{t}$ represent the data and $y_{t}$ its trend, restricted to the form

$$
y_{t}=\left\{\begin{array}{ll}
y_{0} g_{1}^{t} & 0 \leq t \leq \tau \\
y_{0} g_{1}^{\tau} g_{2}^{t-\tau} & \tau \leq t \leq T
\end{array},\right.
$$

where $g_{1}$ and $g_{2}$ denote the growth rates in the first and second growth regimes, and $\tau$ represents the timing of the regime switch. To find the trend, we solve $\min _{y_{0}, g_{1}, g_{2}, \tau} \sum_{t=0}^{T}\left(y_{t}-x_{t}\right)^{2}$. Note that this procedure determines the two growth rates and the timing of the regime switch. Applying this method to both of the TFP time series, we obtain the TFP growth rates characterizing the first part of the trends, $\gamma_{1,1600}=1.042(0.16 \%)$ and $\gamma_{2,1600}=1.006(0.025 \%)$, as well as the endpoint growth rates, $\gamma_{1,1900}=1.126(0.4 \%)$ and $\gamma_{2,1900}=1.174(0.6 \%) \cdot{ }^{34}$

\footnotetext{
${ }^{33}$ See the appendix for a complete description that would allow anyone to reproduce our TFP estimates.

${ }^{34}$ Our estimation results are in line with those in Antras and Voth (2002). In that work, TFP growth in Britain is estimated for the period $1770-1860$, and it is found not to exceed $0.6 \%$ annual rate.
} 
Interestingly, $\gamma_{1,1600}$ and $\gamma_{2,1600}$ yield predictions for the growth rate of the population and per capita output around 1600 (Equation (6)). These predictions, $n=\left(\gamma_{1} \gamma_{2}^{-\frac{1-\phi}{1-\theta}}\right)^{\frac{1}{1-\phi-\mu}}=1.097(0.37 \%)$ and $\gamma=\gamma_{2}^{\frac{1}{1-\theta}}=1.0085(0.00034 \%)$, are consistent with the data, according to which population grew at the annual rate of $0.4 \%$, while output per capita remained roughly constant.

\section{Calibrating the remaining parameters}

The value of preference parameter $\beta$ is determined to be 0.415 from the Euler equation $\gamma=\frac{\beta}{n}[r+1-\delta]$, after we substitute for $\gamma, n$, and the gross interest rate.

Time spent with children $(q n)$ and the relation $\frac{a+b}{a}$, together yield $a=0.085$ and $b=0.256$. Finally, the balanced growth path feasibility equation, $\frac{c}{k}=r \frac{y}{r k}+1-\delta-\gamma n$, gives a prediction for the consumptioncapital ratio. Using $\frac{c}{k}, n, \gamma, q n$ and $\frac{l_{1}}{l}$ along with the data moments, $r, \frac{r k}{y}$ and $\frac{y_{1}}{y}$, in the remaining balanced growth path equation, $\frac{(1-\alpha-\beta)(1-q n)}{\alpha \mu} \frac{y}{y_{1}} \frac{1}{r} \frac{r k}{y} \frac{l_{1}}{l} \rho=q n-\frac{\gamma n}{(r+1-\delta)}$, we obtain $\alpha=0.582$.

The calibrated parameter values are listed in Table 2.

Table 2: Calibrated Parameter Values

\begin{tabular}{|l|l|}
\hline Malthusian Technology: & $A_{10}=100, \gamma_{1,1600}=1.042, \phi=.104, \quad \mu=0.537$ \\
Solow Technology: & $A_{20}=100, \gamma_{2,1600}=1.006, \quad \theta=0.273$ \\
Preferences: & $\alpha=0.582, \beta=0.415$ \\
Cost of Children: & $\pi=0.67, \quad a=0.085, \quad b=0.256$ \\
Other: & $\delta=0.723, \Lambda=1$ \\
\hline
\end{tabular}

\section{Main Results}

Three experiments were conducted within the calibrated framework. In the first experiment (Exp. 1), the growth rates of TFP in the two sectors were varied according to our estimates obtained in Section IV with the young-age mortality held fixed at its 1600 level. In the second experiment (Exp. 2), the probability of surviving to adulthood was varied according to its historical estimates with the growth rates of TFP in both sectors held at their 1600 values. In the third experiment (Exp. 3), the two exogenous changes employed in Exps. 1 and 2 were carried out simultaneously. The experimental values of $\gamma_{1}, \gamma_{2}$ and $\pi$ are plotted in Figures 8-10. Because we do not aim at investigating high frequency behavior, we smoothed the experimental time series. ${ }^{35}$

\footnotetext{
${ }^{35}$ The series for $\pi$ during the period $1612.5-1912.5$ was replaced by its 7 -period MA. The series for $\gamma_{1}$ and $\gamma_{2}$ were modified by fitting a logistic function to the endpoint growth rates to minimize the distance between the estimated TFP time series and the smoothed trend. The smoothing parameter was restricted to be no more than 3 .
} 
The economy starts off on a Malthus-Solow BGP. ${ }^{36}$ Each period in the model represents a specific 25-year period in the data. With the appropriate exogenous change fed into the model, the model was solved for the equilibrium dynamics under the assumption of perfect foresight. ${ }^{37}$ Although different types of limiting behavior of equilibrium time paths are possible in our model, in all three experiments, the solution converged to a Solow BGP. ${ }^{38}$ Figures 11-19 depict the results of the experiments. The dotted curves represent the time paths of relevant variables in the data. The remaining curves represent their model counterparts, resulting from each of the experiments. The results are summarized in Table 3.

Table 3: Main Results

\begin{tabular}{|l|r|rrr|r|rrr|}
\hline & \multicolumn{4}{|c|}{$1600-1950$} & \multicolumn{4}{|c|}{$1650-1950$} \\
\cline { 2 - 9 } & & \multicolumn{2}{|c|}{ \%Accounted for by Model } & & \multicolumn{3}{c|}{ \%Accounted for by Model } \\
& $\% \triangle$ in Data & Exp. 1 & Exp. 2 & Exp. 3 & \% $\triangle$ in Data & Exp. 1 & Exp. 2 & Exp. 3 \\
\hline \hline$y$ & 379.55 & 68.34 & 2.23 & 65.78 & 348.89 & 72.77 & 1.68 & 69.33 \\
CBR & -48.73 & -0.24 & 44.67 & 45.85 & -39.95 & -0.00 & 59.06 & 60.72 \\
GFR & -46.28 & -0.56 & 41.35 & 44.23 & -36.45 & -0.01 & 56.91 & 61.10 \\
$\frac{\rho \Lambda}{y}$ & -95.32 & 92.26 & -1.97 & 91.90 & -95.68 & 91.90 & -0.89 & 91.68 \\
$\frac{w l}{y}$ & 16.67 & 111.93 & -2.39 & 111.51 & 20.69 & 90.05 & -0.88 & 90.95 \\
$\frac{y 2}{y}$ & 187.88 & 95.03 & -2.03 & 94.70 & 177.38 & 100.35 & -1.00 & 103.30 \\
$\frac{l}{l}$ & 137.25 & 98.18 & -2.54 & 97.89 & 113.26 & 118.61 & -1.46 & 122.17 \\
\hline
\end{tabular}

\section{Experiment 1: Changes in the growth rates of TFP}

The results of this experiment lead us to conclude that changes in the productivity in the two sectors represent an important force behind the observed patterns in per capita income, the level of industrialization and urbanization, and patterns of labor, capital, and land shares in the total income. By contrast, changes in productivity are found to be quantitatively unimportant in driving fertility behavior.

Acceleration of TFP generates a transition from the early stagnation to modern growth. Around 1600, the growth rate of per capita GDP is near zero. It then takes off around 1800 and exhibits a sustained growth of nearly $1 \%$ per year. The increase in per capita GDP obtained in this experiment is

\footnotetext{
${ }^{36}$ This assumption, given the calibrated parameter values, pins down the initial conditions, $N_{0}$ and $k_{0}$.

${ }^{37}$ The solution method is described in the Supplemental Notes. Briefly, the objective is to find time paths that satisfy the first order, feasibility and transversality conditions. Because the original variables exhibit exponential growth, we work with detrended variables. Since our experiments involve parameter changes, a bifurcation of the dynamical system, i.e., a qualitative change in the type of a BGP towards which convergence takes place, is possible. This forces us to use a non-standard detrending method.

${ }^{38}$ For each of the three experiments, the asymptotic BGP towards which convergence takes place is locally stable (possessing a single eigen value which is less than 1). This can be understood by noting that If the Malthusian technology is removed, $N_{t}$ is no longer a state variable. In this case, the only state variable is $k_{t}$ and the condition that exactly one eigen value be less that 1 is necessary and sufficient for local stability of the BGP towards which convergence takes place.
} 
approximately $73 \%$ of the actual increase in the English per capita GDP during the period $1650-1950$.

TFP acceleration also drives the process of industrialization and urbanization ${ }^{39}$ (see Figures 14 and 15). As the Solow TFP begins to grow more rapidly than the Malthusian TFP, the Solow sector employs an increasingly larger fraction of the available resources, the equilibrium paths converging to a Solow BGP. As a result of successfully capturing factor reallocation, this experiment also accounts for over $90 \%$ of long-term trends in the observed income shares.

Interestingly, we find that changes in productivity have a very small quantitative impact on fertility behavior (see Figures 12 and $13^{40}$ ). Because children are normal goods, higher income growth exherts upward pressure on fertility. TFP acceleration also causes an increase in the cost of rearing children through both channels: a rising time cost measured in terms of wages and parents choosing to have higher quality children. Indeed, we can interpret $k_{t+1}$ as a measure of quality, and the ratio $k_{t+1} / y_{t}$ increases from 0.0675 to 0.113 . We find that these two effects nearly offset each other. Through their combined influence, fertility rises slightly, and then declines, with the overall change being small. Similarly, this experiment yields a quantitatively insignificant hump in the population growth rate (see Figure 19). Starting at the calibrated level of a $0.37 \%$ annual rate, the population growth rate increases slightly, and then decreases, converging to a $0.36 \%$ annual rate in the limit.

The limiting behavior of the equilibrium time paths is summarized by $y_{t+1} / y_{t} \rightarrow 1.0088, N_{t+1} / N_{t} \rightarrow$ $1.0036, r_{t} \rightarrow 1.045$, and $c_{t} / k_{t} \rightarrow 0.398$, given in annualized rates.

\section{Experiment 2: Changes in young-age mortality}

The results of this experiment suggest that changes in young-age mortality were an important driving force behind the demographic transformation in England but had little bearing on the economic changes that took place during the period $1650-1950$.

Because every child requires an investment of time from the parents, declining young-age mortality lowers the time cost of surviving children, thus relaxing the budget constraint and allowing parents to optimally adjust fertility and the quality of surviving children. Parents do choose to raise higher quality children as the ratio $k_{t+1} / y_{t}$ increases from 0.0675 to 0.1021 . Finally, fertility is pressured downwards, because with more newborns living to adulthood, fewer births are needed to realize the desired number of surviving children. The downward pressure on birth rates appears to be stronger overall, as changes in

\footnotetext{
${ }^{39}$ Levels of urbanization and industrialization are imperfect data counterparts of $l_{2} / l$ and $y_{2} / y$ in our model. The main reason is that in the data, rural output is not a perfect substitute for the non-rural output, while in the model the Malthusian good is a perfect substitute for the Solow good. It is nonetheless instructive to make these comparisons.

${ }^{40}$ To compare the results of the experiments to the data we use a 3-period MA representation of CBR and GFR.
} 
young-age mortality account for roughly $60 \%$ of changes in CBR and GFR during 1650 - 1950. Although the population growth rate does increase from $0.37 \%$ to $0.8 \%$, this increase is small. It is important to note that since we do not model changes in adult mortality, which greatly affect population growth, we deem it more appropriate to resort to comparing model's predictions to fertility behavior. ${ }^{41}$ For the same reason we do not consider net reproduction rate, as it explicitly takes into account maternal mortality over her lifecycle.

Figure 16 displays the time series for the level of industrialization in the model and in the data using a longer time scale. We see that as $\pi$ increases, the time spent on raising surviving children decreases, freeing up time for work. This results in the relative expansion of the labor-intensive urban sector, but the reallocation of resources occurs slowly. Even in 2400, as much as $10 \%$ of the total output is still produced in the rural sector. The relation between the behavior of the level of urbanization exhibited in the model and in the data is very similar. Changes in the probability of survival are also found to be quantitatively insignificant in accounting for patterns in the GDP per capita (see Figure 11).

The limiting behavior of equilibrium time paths is summarized by $y_{t+1} / y_{t} \rightarrow 1.00034, N_{t+1} / N_{t} \rightarrow$ $1.008, r_{t} \rightarrow 1.04$, and $c_{t} / k_{t} \rightarrow 0.357$.

\section{Experiment 3: Simultaneous Change in both Quantities}

When both the TFP growth rates and young-age mortality are varied simultaneously in accordance with their historical estimates, the result is nearly a simple sum of changes generated by the first two experiments. The limiting behavior of the equilibrium time paths in this case is summarized by $y_{t+1} / y_{t} \rightarrow$ $1.0088, N_{t+1} / N_{t} \rightarrow 1.008, r_{t} \rightarrow 1.05$, and $c_{t} / k_{t} \rightarrow 0.45$.

\section{Sensitivity Analysis}

\section{TFP estimates}

Recall that the time series of TFP growth rates were estimated on the basis of the data up to 1915. For later years, TFP in both sectors was assumed to retain the same constant growth trends. Would changes in TFP growth rates be more successful in accounting for the demographic and economic changes if the growth rate of TFP increased further since 1915? In this sensitivity exercise, we repeat Exp. 1 and 3, but this time with the Solow TFP series updated to guarantee that the model captures the growth rate of per capita income in the 20th century (1.4\%). Because there is convergence to the Solow BGP, we can

\footnotetext{
${ }^{41}$ Recall that the observed hump in the English population growth rate resulted from the fact that CDR fell before CBR.
} 
determine $\gamma_{2,1900}$ using $\gamma=\gamma_{2,1900}^{\frac{1}{1-\theta}}=1.4156(1.4 \%)$. This yields $\gamma_{2,1900}=1.2755(0.98 \%)$, in contrast to $1.174(0.64 \%)$, used in the original experiments. The original result, that changes in the TFP growth rates drive the economic transformation while having a negligible effect on birth rates, is reconfirmed (Table 4).

Table 4: Sensitivity to the Endpoint Solow TFP Growth, $\gamma_{2,1900}=1.2755$

\begin{tabular}{|l|r|r|r|r|}
\hline & \multicolumn{3}{|c|}{ \%Accounted for by Model } \\
\hline & \multicolumn{2}{|c|}{$1600-1950$} & \multicolumn{2}{|c|}{$1650-1950$} \\
\hline & Exp. 1 & \multicolumn{1}{|c|}{ Exp. 3 } & Exp. 1 & \multicolumn{1}{|c|}{ Exp. 3 } \\
\hline \hline$y$ & 81.93 & 79.03 & 87.34 & 83.42 \\
CBR & -0.26 & 45.88 & -0.03 & 60.75 \\
GFR & -0.61 & 44.29 & -0.07 & 61.18 \\
$\frac{\rho \Lambda}{y}$ & 95.88 & 95.59 & 95.51 & 95.31 \\
$\frac{w l}{y}$ & 116.32 & 115.98 & 93.58 & 94.56 \\
$\frac{y 2}{y}$ & 98.76 & 98.50 & 104.30 & 107.40 \\
$\frac{l_{2}}{l}$ & 101.40 & 101.17 & 122.51 & 126.22 \\
\hline
\end{tabular}

\section{Barro and Becker parental utility}

As proved in the appendix, the parental utility used here, $U_{t}\left(c_{t}, n_{t}, U_{t+1}\right)=\alpha \log c_{t}+(1-\alpha) \log n_{t}+$ $\beta U_{t+1}$, is a special case of the Barro and Becker parental utility, $U_{t}\left(c_{t}, n_{t}, U_{t+1}\right)=c_{t}^{\sigma}+\beta n_{t}^{1-\varepsilon} U_{t+1}$, realized when $\sigma \rightarrow 0$ and $\frac{1-\varepsilon-\sigma}{\sigma}=\frac{1-\alpha-\beta}{\alpha \beta}$. Note that this implies that $\varepsilon \rightarrow 1$. A natural question is whether our main results would change if we used the Barro and Becker parental utility form with $\sigma>0$ and $\varepsilon<1$. Below we investigate this point.

First we recalibrated the model under the assumption of the Barro and Becker utility ${ }^{42}$, using the procedure similar to that described in Section IV, with the only difference being that the calibration precedure used here does not fix both $\varepsilon$ and $\sigma$. Instead, it fixes $\frac{1-\varepsilon-\sigma}{\sigma}=0.0129$, thus allowing us to choose $\varepsilon$. We performed experiments using several values of $\varepsilon$ in the admissible range of $(0,1)$. For $\varepsilon=0.9$, which implies that $\sigma=0.0987$, the results are very close to the original results. Here we report the results for a more extreme case, with $\varepsilon=0.7$ (and hence $\sigma=0.2962$ ).

In this case, again we find the demographic transition is driven mainly by changes in young-age mortality, while the economic transformation is driven mainly by technological progress. However, here we observe that the overall effect on birth rates is weakened.

Sensitivity to $\delta,(a+b) / a$, and qn.

\footnotetext{
${ }^{42}$ We describe the solution and calibration of the model under the assumption of the Barro and Becker parental utility in the Supplemental Notes.
} 
Table 5: Sensitivity to the Choice of Parental Utility, Barro and Becker form

\begin{tabular}{|l|rrr|rrr|}
\hline & \multicolumn{6}{|c|}{ \%Accounted for by Model } \\
\cline { 2 - 7 } & \multicolumn{3}{|c}{$1600-1950$} & \multicolumn{3}{c|}{$1650-1950$} \\
& Exp. 1 & Exp. 2 & Exp. 3 & Exp. 1 & Exp. 2 & Exp. 3 \\
\hline \hline$y$ & 61.45 & 1.09 & 55.80 & 65.58 & 0.34 & 58.49 \\
CBR & -8.20 & 41.01 & 36.67 & -9.38 & 54.26 & 49.62 \\
GFR & -19.77 & 32.17 & 20.53 & -23.53 & 44.40 & 31.22 \\
$\frac{\rho \Lambda}{y}$ & 97.64 & -1.46 & 97.42 & 97.26 & 0.22 & 97.16 \\
$\frac{w l}{y}$ & 118.45 & -1.77 & 118.23 & 95.27 & 0.22 & 97.07 \\
$\frac{y 2}{y}$ & 100.57 & -1.51 & 100.45 & 106.14 & 0.25 & 111.45 \\
$\frac{l_{2}}{l}$ & 102.96 & -1.93 & 102.87 & 124.32 & 0.26 & 130.59 \\
\hline
\end{tabular}

We find that all of the quantitative results obtained here are extremely robust with respect to changes in $\delta$. Since the estimates of $\delta$ vary from $2.5 \%$ to $15 \%$ in the literature, as mentioned above, we investigated $\delta$ in this range.

Recall that $(a+b) / a$ is an estimate of the average time cost of surviving children relative to that of non-surviving children. This quantity only affects the calibration of $a$ and $b$, and it has no bearing on $q$. In particular, $a$ decreases and $b$ increases in $(a+b) / a$. An increase of $(a+b) / a$ causes a slight increase of the importance of $\pi$ in driving the fertility behavior. We examined values of $(a+b) / a$ ranging from 1 to 7 , and we found that the results were not affected significantly.

Finally, we set the fraction of time spent raising children, $q n$, to 0.42 . Unfortunately, for $q n \leq 0.411$, we have $1-\alpha-\beta<0$, or equivalently $1-\varepsilon-\sigma<0$ for the Barro-Becker preferences, which implies that the Planner's utility decreases as the population increases. Although this does not imply that the Planner will set the population size to 0, as households would still be valued as a factor of production, strict concavity of the objective function would not be guaranteed. For this reason, we only analyzed values of $q n$ in the range $[0.411-0.7]$. For this range, we found little quantitative dependence of the main results on the choice of $q n$.

\section{Conclusion}

We developed a general equilibrium model with endogenous fertility in order to study the roles played by changes in young-age mortality and technological progress in the demographic transition and industrialization in England. We found that the decline in young-age mortality was an important force behind the fall in fertility, while changes in productivity drove the economic transformation. These results suggest that the demographic and economic changes transpired through distinct channels. One policy implica- 
tion of our findings is that improving health technology in sub-Saharan African countries would by itself provide little help to ameliorate the poverty level, although it would help to reduce birth rates.

The main contribution of this work is to provide a thorough quantitative analysis of the productivity and the young-age mortality channels in a framework that allows for a straightforward mapping of the observables into the parameters of the model. Future work, in our opinion, should be directed at merging the promising field of unified growth theory with more thorough quantitative analysis. In particular, insightful mechanisms, such as those put forth by Galor and Weil (2000), Greenwood and Seshadri (2002), Soares (2005), or Kalemli-Ozcan (2002) (that provide additional channels through which mortality and technological progress can influence reproductive choices and economic development), must be applied in manners that are more closely guided by the historical data through modification of models as well as innovative approaches to deriving useful information from the available data.

\section{APPENDIX}

Data Sources ${ }^{43}$

Fraction of non-rural labor in total labor $\left(L_{2} / L\right)$ : [1565-1865] - Clark (2001a), Table 1, p. 8 (England); [1820 - 1992] - Maddison (1995), p. 253 (UK).

Index of Real GDP per capita (y): [1565-1865] - Clark (2001a), Table 7, p. 30, rescaled to equal 100 in 1565 (England and Wales); [1820-1990] - Maddison (1995), p. 194, rescaled to match Clark's index in $1850(\mathrm{UK})$.

Labor Share in Total Income $(w L / Y)$ : [1585 - 1865] - Clark (2001a), Table 9, p. 46 (England); [1924 - 1973] - Matthews et al. (1982), p. 164 (UK); Average for [1973 - 1982] - Maddison (1987), p. 659 (UK); 1992 - Gollin (2002), p. 470, Table 2, Adjustment 3 (UK).

Land Share in Total Income $(\rho \Lambda / Y)$ : [1585 - 1865] - Clark (2001a), Table 9, p. 46 (England); [1873 - 1913] - Matthews et al. (1982), p. 643 (UK); [1987 - 1998] - UK National Statistics.

Capital Share in Total Income: Imputed according to the relation $r K / Y=1-w L / Y-\rho \Lambda / Y$.

Fraction of non-rural output in total output $\left(Y_{2} / Y\right)$ : [1555-1865] Imputed by dividing the nominal net farm output (alternative labor) obtained from Clark (2002), Table 4, p. 14 (England), by the nominal

\footnotetext{
${ }^{43}$ Due to data limitations for England, we were forced to draw on the data sources available for England and Wales and UK. Although this inconsistency introduces some degree of error, we believe that it is small for the following reasons. (1) We do not consider level variables, such as GDP or population size, but instead growth rates, indices, and fractions of level variables. (2) For the period under consideration, the population of Wales is less than $6 \%$ of that of England. (3) Scotland's population size relative to that of England and Wales falls from $17 \%$ in 1820 (the earliest date for which we are forced to use UK data sources) to less than $10 \%$ today. (4) Appropriate rescaling was made in all cases.
} 
GDP obtained from Clark (2001a), Table 3, p. 19 (England and Wales), but adjusted for population differential between England and Wales, with the resulting fraction indexed to match Mitchell's estimates in 1800; [1788-1991] - Mitchell, 1978 (UK)

Crude Birth and Crude Death Rates: [1541 - 1871] - Wrigley et al. (1997) (England); [1871 - 1986] Mitchell, 1978 (England and Wales).

General Fertility Rate: Computed using CBR and the fraction of females in the total population, taken from Wrigley et al. (1997) for [1541 - 1841] (England) and Human Mortality Database for [1841 1999] (England and Wales).

Population Growth Rate: [1541 - 1836] - Wrigley et al. (1997) (England); [1841 - 1999] - Human Mortality Database (England and Wales).

Age-specific survival probabilities: [1580-1837] - Wrigley et al. (1997) (England); [1841 - 1999] Human Mortality Database (England and Wales).

Data used in TFP Estimation: See the appendix on TFP estimation.

\section{Barro and Becker vs. Lucas Utility}

Proposition 2 The form of the parental utility used in Lucas (2002), $U_{t}\left(c_{t}, n_{t}, U_{t+1}\right)=\alpha \log c_{t}+$ $(1-\alpha) \log n_{t}+\beta U_{t+1}$, represents the same preferences as the Barro and Becker utility, $U_{t}\left(c_{t}, n_{t}, U_{t+1}\right)=$ $c_{t}^{\sigma}+\beta n_{t}^{1-\varepsilon} U_{t+1}$, if $\sigma \rightarrow 0$ and $\frac{1-\varepsilon-\sigma}{\sigma}=\frac{1-\alpha-\beta}{\alpha \beta}$.

Proof. Let $\frac{1-\varepsilon-\sigma}{\sigma}=\frac{1-\alpha-\beta}{\alpha \beta}$. Consider the following transformation of the Barro and Becker utility, $W_{t}\left(c_{t}, n_{t}, U_{t+1}\right)=(1-\beta) U_{t}\left(c_{t}, n_{t}, U_{t+1}\right):$

$$
W_{t}\left(c_{t}, n_{t}, W_{t+1}\right)=(1-\beta) c_{t}^{\sigma}+\beta n_{t}^{1-\varepsilon} W_{t+1}
$$

Next, consider the transformation, $V_{t}\left(c_{t}, n_{t}, W_{t+1}\right)=W_{t}\left(c_{t}, n_{t}, W_{t+1}\right)^{\frac{\alpha}{(1-\beta) \sigma}}$, given by

$$
V_{t}\left(c_{t}, n_{t}, V_{t+1}\right)=\left[(1-\beta) c_{t}^{\sigma}+\beta n_{t}^{1-\varepsilon} V_{t+1}^{\frac{(1-\beta) \sigma}{\alpha}}\right]^{\frac{\alpha}{(1-\beta) \sigma}}=\left(\left[(1-\beta) c_{t}^{\sigma}+\beta\left(n_{t}^{\frac{1-\varepsilon}{\sigma}} V_{t+1}^{\frac{(1-\beta)}{\alpha}}\right)^{\sigma}\right]^{\frac{1}{\sigma}}\right)^{\frac{\alpha}{(1-\beta)}}
$$

Now, taking the limit $\sigma \rightarrow 0$ while varying $\varepsilon$ in such a manner that $\frac{1-\varepsilon-\sigma}{\sigma}=\frac{1-\alpha-\beta}{\alpha \beta}$, we have

$$
\lim _{\sigma \rightarrow 0} V_{t}\left(c_{t}, n_{t}, V_{t+1}\right)=\left(\lim _{\sigma \rightarrow 0}\left[(1-\beta) c_{t}^{\sigma}+\beta\left(n_{t}^{\frac{1-\varepsilon}{\sigma}} V_{t+1}^{\frac{(1-\beta)}{\alpha}}\right)^{\sigma}\right]^{\frac{1}{\sigma}}\right)^{\frac{\alpha}{(1-\beta)}}=\left(c_{t}^{1-\beta}\left(n_{t}^{\frac{1-\varepsilon}{\sigma}} V_{t+1}^{\frac{(1-\beta)}{\alpha}}\right)^{\beta}\right)^{\frac{\alpha}{(1-\beta)}}
$$


Note that $n_{t}^{\frac{1-\varepsilon}{\sigma}}$ and $V_{t+1}^{\frac{(1-\beta)}{\alpha}}$ remain fixed as $\sigma \rightarrow 0$. Consider the final transformation, $U_{t}\left(c_{t}, n_{t}, V_{t+1}\right)=$ $\log V_{t}\left(c_{t}, n_{t}, V_{t+1}\right)$, which takes the form

$$
U_{t}\left(c_{t}, n_{t}, U_{t+1}\right)=\frac{\alpha}{(1-\beta)}\left[(1-\beta) \log c_{t}+\frac{1-\varepsilon}{\sigma} \beta \log n_{t}+\frac{(1-\beta)}{\alpha} \beta U_{t+1}\right]
$$

Simplifying and using the assumption that $\frac{1-\varepsilon-\sigma}{\sigma}=\frac{1-\alpha-\beta}{\alpha \beta}$, i.e., $\frac{1-\varepsilon}{\sigma}=\frac{(1-\alpha)(1-\beta)}{\alpha \beta}$, we obtain

$$
\begin{aligned}
U_{t}\left(c_{t}, n_{t}, U_{t+1}\right) & =\alpha \log c_{t}+\frac{\alpha}{(1-\beta)} \frac{(1-\alpha)(1-\beta)}{\alpha \beta} \beta \log n_{t}+\beta U_{t+1} \\
& =\alpha \log c_{t}+(1-\alpha) \log n_{t}+\beta U_{t+1} .
\end{aligned}
$$

Cost of Raising Children, Measuring $(a+b) / a$

In this appendix we explain our method of determining the average time cost of a surviving child relative to that of a non-surviving child, $(a+b) / a=4$. Denoting the momentary cost of raising a child by $p(t)$, the total cost of raising a child to age $\tau$ is given by $c(\tau)=\int_{0}^{\tau} p(t) d t$. Under the assumption that the momentary cost is a decreasing linear function of the form $p(t)=\eta-\frac{\eta}{25} t$, we have $c(\tau)=\tau \eta-\frac{\tau^{2}}{50} \eta$ and the total cost of raising a surviving child becomes $a+b=c(25)=25 \eta-\frac{25^{2}}{50} \eta=12.5 \eta$.

Figure 20 displays the age specific mortality distribution for people who died before reaching age 25 in early 17th century England. The five groups here correspond to the age ranges 0-1, 1-5, 5-10, 10-15, and 15-25. (Below, we refer to the beginning and ending ages of the $i$ th group as $A_{i}^{b}$ and $A_{i}^{e}$, respectively.) In the figure, for example, the first point indicates that of all the people who died before reaching age 25, $45 \%$ died before age 1 . The pattern of age-specific mortality, conditional on dying before age 25 , persists throughout the years considered in this paper and, in fact, is similar to that in present-day UK. Then, assigning to every child belonging to group $i$ the time cost associated with a child that dies at age $\frac{A_{i}^{b}+A_{i}^{e}}{2}$, we obtain

$$
\begin{aligned}
a & =0.45 c(0.5)+0.22 c(3)+0.12 c(7.5)+0.05 c(12.5)+0.16 c(20)=4 \eta, \\
b & =12.5 \eta-4 \eta=8.5 \eta
\end{aligned}
$$

It follows that $\frac{b}{a}=2.15$ and $\frac{a+b}{a}=3.15$. If, instead, we assign to each child in group $i$ the time cost associated with a child that dies at age $A_{i}^{b}$, we find $\frac{b}{a}=3.45$, and hence $\frac{a+b}{a}=4.45$. Finally, beause it is reasonable to assume that the average age of death for the children belonging to a given group is closer 
to $A_{i}^{b}$ than to $A_{i}^{e}$, we choose the value $\frac{a+b}{a}=4$; this corresponds to the assumption that all children belonging to each group $i$ die at age $A_{i}^{b}+0.1\left(A_{i}^{e}-A_{i}^{b}\right)$.

\section{Estimation of TFP Time Series}

Given the calibrated calibrated values of $\phi, \mu$ and $\theta$ and using the assumption of profit maximization, we back out the time series for $A_{1 t}$ and $A_{2 t}$ given by (7) and (8), where $r_{t}$ is the rental rate of capital $(\% / 100), w_{t}$ is the real wage (final goods per unit of labor), and $\rho_{t}$ is the rental price of land (final goods per acre).

We work with historical data for $r_{t}(\% / 100), \omega_{1 t}$ (nominal rural wages in $£$ ), $\tilde{\rho}_{t}$ (rental rate of land in $\% / 100$ ), $P_{\Lambda t}$ (price of land in $£ /$ acre), and the GDP deflator, $P_{t}$. These series yield the real wage and the rental price of land through the identities $w_{i t}=\frac{\omega_{i t}}{P_{t}}$ and $\rho_{t}=\frac{\tilde{\rho}_{t} P_{\Lambda t}}{P_{t}}$.

The GDP deflator, $P_{t}$, is obtained from Table 9 in Clark (2001a), and for the time period 1875-1910, it is imputed under the assumption that it grew at the same rate as the agricultural prices given in Table 1 of Clark (2002).

Table 1 in Clark (2002) contains nominal wages in the rural sector $\omega_{1 t}$ (pence per day). Dividing these time series by 240 changes the units into pounds. Further, multiplying the resulting time series by 300 gives the annual nominal wage, $\omega_{1 t}$, under the assumption that 300 days are worked per year. We infer $\omega_{2 t}$ using the time series for the wage bill in the rural sector, $\omega_{1} L_{1}$, the total wage bill in the economy, $\omega_{1} L_{1}+\omega_{2} L_{2}$, the fraction of rural labor in total labor, $\frac{L_{1}}{L}$, and the identity $\frac{\omega_{1} L_{1}+\omega_{2} L_{2}}{\omega_{2} L_{2}}=\frac{\omega_{1} L_{1}}{\omega_{2} L_{2}}+1$, which implies $\omega_{2}=\frac{\omega_{1}}{\frac{\omega_{1} L_{1}+\omega_{2} L_{2}}{\omega_{2} L_{2}}-1} \frac{1}{\frac{1}{L_{1}}-1}$.

The time series of the wage bill in the rural sector, $\omega_{1} L_{1}$, is given in Table 3 of Clark (2002). The total wage bill in the economy, $\omega_{1} L_{1}+\omega_{2} L_{2}$, is taken from Table 3 in Clark (2001a), and for the period 18751910 , it is imputed using the time series of $\omega_{1} L_{1}$ and the assumption that the ratio $\omega_{1} L_{1} /\left(\omega_{1} L_{1}+\omega_{2} L_{2}\right)$ continued to fall at the same rate as it did between 1865 and 1875. The fraction of the total labor constituted by rural labor, $\frac{L_{1}}{L}$, is obtained from Table 1 of Clark (2001a), and for the period 1875-1910 from Maddison (1995) (page 253).

Having obtained $\omega_{1 t}$ and $\omega_{2 t}$, we back out real wages according to the relation $w_{i t}=\frac{\omega_{i t}}{P_{t}}$.

We obtain $\tilde{\rho}_{t}$ (rental rate of land in \%/100) from Table 2 in Clark (2002). Following Clark (2002) (p. 6 ), we infer $r_{t}=\tilde{\rho}_{t}+0.04$, allowing $1.5 \%$ for risk premium and $2.5 \%$ for depreciation.

Table 4 in Clark (2002b) provides us with "Total Land Rents and Local Taxes," which represents $\tilde{\rho}_{t} P_{\Lambda t} \Lambda$, where $P_{\Lambda t}$ is the price of land, $£ /$ acre. Dividing this time series by $\Lambda=26.524 \mathrm{M}$ acres, taken 
from Clark (2002) (p. 10), and by $P_{t}$, we obtain $\rho_{t}=\frac{\tilde{\rho}_{t} P_{\Lambda t}}{P_{t}}$.

Mapping of the Model to the Data: Population Size, CBR, GFR

We need to estimate the average size of the population in period $t$. The number of adults is constant at $2 N$ over the duration of a period. The number of children changes during each period due to child mortality. In the beginning of each period, $2 f N$ children are born. Using age-specific child mortality rates for the age groups $0-1,1-5,5-10,10-15,15-25$ and the simplifying assumption made above that all children belonging to group $i$ die at age $A_{i}^{b}+\nu\left(A_{i}^{e}-A_{i}^{b}\right)$, with $\nu=\frac{1}{10}$, we compute the average population size in each period according to

$$
\begin{aligned}
P= & 2 N+\left[\left(\nu+(1-\nu) \pi_{0}^{1}\right)+4\left(\nu \pi_{0}^{1}+(1-\nu) \pi_{0}^{5}\right)+5\left(\nu \pi_{0}^{5}+(1-\nu) \pi_{0}^{10}\right)\right. \\
& \left.+5\left(\nu \pi_{0}^{5}+(1-\nu) \pi_{0}^{10}\right)+10\left(\nu \pi_{0}^{5}+(1-\nu) \pi_{0}^{25}\right)\right] \frac{1}{25} 2 f N .
\end{aligned}
$$

The model counterpart of CBR is then given by $C B R=1000 \frac{2 f N}{P}$. Further, GFR is computed as $G F R=$ $1000 \frac{2 f N}{N}=2000 f$.

\section{References}

Allen, Robert. Enclosure and the Yeoman, Oxford: Clarendon Press, 1992.

Antras, Pol and Voth, Hans-Joachim. "Factor Prices and Productivity Growth during the British Industrial Revolution" Explorations in Economic History, January 2003, 40, pp. 52-77.

Bar, Michael and Leukhina, Oksana "Supplemental Notes to Demographic Transition and Industrial Revolution: A Macroeconomic Investigation.” On-line supplement available at www.unc.edu/ oksana, December 2006.

Barro, Robert J. and Becker, Gary S. "Fertility Choice in a Model of Economic Growth." Econometrica, March 1989, 57(2), pp. 481-501.

Becker, Gary S.; Glaeser, Edward L. and Murphy, Kevin M. "Population and Economic Growth." American Economic Review, May 1999 (Papers and Proceedings), 89(2), pp. 145-149.

Becker, Gary S. and Lewis, H. Gregg. "On the Interaction between Quantity and Quality of Children." Journal of Political Economy, March-April, 1973, 81(2, part 2), S279-S288. 
Boldrin, Michele and Jones, Larry E. "Mortality, Fertility and Saving in a Malthusian Economy." Review of Economic Dynamics, October 2002, 5(4), pp. 775-814.

Bos, Eduard and Bulatao, Rodolfo A. "Projecting Fertility for All Countries." Policy, Research, and External Affairs Working Paper 500. World Bank, 1990.

Boucekkine, Raouf; De la Croix, David and Peeters, Dominique. "Early Literacy Achievements, Population Density and the Transition to Modern Growth." Unpublished manuscript, 2005.

Chesnais, Jean-Claude. The Demographic Transition, Oxford: Clarendon Press, 1992.

Clark, Gregory. "The Secret History of the Industrial Revolution." Unpublished Manuscipt, 2001a. . "Debt, Deficits, and Crowding out: England, 1727-1840." European Review of Economic History, December 2001b, 5, pp. 403-436.

- "The Agricultural Revolution and the Industrial Revolution: England, 1500-1912." Unpublished Manuscipt, 2002.

Doepke, Matthias. "Accounting for Fertility Decline during the Transition to Growth." Journal of Economic Growth, September 2004a, 9(3), pp. 347-383.

• "Child Mortality and Fertility Decline: Does the Barro-Becker Model fit the Facts?" Journal of Population Economics, June 2005, 18(2), pp. 337-366.

Ehrlich, Isaac and Lui, Francis. "Intergenerational Trade, Longevity, Intrafamily Transfers and Economic Growth." Journal of Political Economy, October 1991, 99(5), pp. 1029-59.

Fernandez-Villaverde, Jesus. "Was Malthus Right? Economic Growth and Population Dynamics." Unpublished Manuscript, 2001.

Floud, Roderick and Johnson, Paul. The Cambridge Economic History of Modern Britain. Cambridge University Press, 2004, volumes 1-3.

Galor, Oded. "From Stagnation to Growth: Unified Growth Theory." Forthcoming in Handbook of Economic Growth (Aghion, Philippe and Durlauf, Steven, eds.), 2005

Galor, Oded and Weil, David N. "Population, Technology, and Growth: From Malthusian Stagnation to the Demographic Transition and Beyond." American Economic Review, September 2000, 90(4), pp. 806-828.

Golosov, Mikhail; Jones, Larry E. and Tertilt, Michele. "Efficiency with Endogenous Population Growth." Forthcoming in Econometrica, 2006. 
Greenwood, Jeremy and Seshadri, Ananth. "The U.S. Demographic Transition." American Economic Review, May 2002 (Papers and Proceedings), 92(2), pp.153-159.

Gollin, Douglus. "Getting Income Shares Right." Journal of Political Economy, 2002, 110(2), pp. $458-474$.

Hansen, Gary D. and Prescott, Edward C. "Malthus to Solow." American Economic Review, September 2003, 92(4), pp. 1205-1217.

Hotz, Joseph V.; Klerman, Jacob Alex and Willis, Robert J. "The Economics of Fertility in Developed Countries" Handbook of Population and Family Economics (Rosenzweig, Mark R. and Stark, Oded, eds.). Amsterdam: Elsevier Science B.V., 1997, volume 1A, pp. 275-347.

Human Mortality Database, http://www.mortality.org.

Jones, Charles. "Was an Industrial Revolution Inevitable? Economic Growth over the Very Long Run." Advances in Macroeconomics, 2001, 1(2), pp. 1028-1028.

Kalemli-Ozcan, Sebnem. "Does the Mortality Decline Promote Economic Growth?" Journal of Economic Growth, December 2002, 7(4), pp. 411-439.

Kalemli-Ozcan, Sebnem; Ryder, Harl E. and Weil, David N. "Mortality Decline, Human Capital Investment and Economic Growth." Journal of Development Economics, June 2002, 62(1), pp. 1-23.

Lagerlof, Nils-Petter. "From Malthus to Modern Growth: Can Epidemics Explain the Three Regimes?" International Economic Review, May 2003, 44(2), pp. 755-777.

. "The Galor-Weil Model Revisited: A Quantitative Exercise." Review of Economic Dynamics, January 2006, 9(1), pp. 116-142.

Lee, Ronald D. "Demographic Transition." The New Palgrave Dictionary of Economics, (Durlauf, S.N. and Blume, L.E., eds.). Palgrave Macmillan, (forthcoming).

Lucas, Robert E. "The Industrial Revolution: Past and Future." Lectures on Economic Growth, Cambridge: Harvard University Press, 2002.

Maddison, Angus. "Growth and Slowdown in Advanced Capitalist Economies: Techniques of Quantitative Assessment." Journal of Economic Literature, June 1987, 25(2), pp. 649-698. . Monitoring the World Economy: 1820/1992. Washington: OECD Development Center, 1995.

Mason, Karen. "Explaining Fertility Transitions." Demography, November 1997a, 34(4), pp. 443-454. 
Matthews, Robert C.O.; Feinstein, C.H. and Odling-Smee, John C. British Economic Growth: 1856-1973. Stanford: Stanford University Press, 1982.

Mitchell, Brian R. European Historical Statistics 1750-1970. New York: Columbia University Press, 1975.

Sah, Raaj K. "The Effects of Child Mortality Changes on Fertility Choice and Parental Welfare." Journal of Political Economy, June 1991, 99(3), pp. 582-606.

Schultz, T. Paul. "Demand for Children in Low Income Countries." Handbook of Population and Family Economics (Rosenzweig, Mark R. and Stark, Oded, eds.). Amsterdam: Elsevier Science B.V., 1997, volume $1 \mathrm{~A}$, pp. 349-430.

Soares, Rodrigo R. "Mortality Reductions, Educational Attainment, and Fertility Choice." American Economic Review, June 2005, 95(3), pp. 580-601.

Tamura, Robert F. "Human Capital and Economic Development." Journal of Development Economics, 2006, 79(1), pp. 26-72.

U.K. National Statistics, http://www.statistics.gov.uk/

Wilson, Chris and Woods, Robert. "Fertility in England: A Long-Term Perspective." Population Studies, November 1991, 45(3), pp. 399-415.

Wolpin, Kenneth I. "Determinants and Consequences of the Mortality and Health of Infants and Children." Handbook of Population and Family Economics (Rosenzweig, Mark R. and Stark, Oded, eds.). Amsterdam: Elsevier Science B.V., 1997, volume 1A, pp. 483-557.

Woods, R. I. "Approaches to the Fertility Transition in Victorian England." Population Studies, July 1987, 41(2), pp. 283-311.

Wrigley, E.A.; Davies, R.S.; Oeppen, J.E. and Schofield, R.S. English Population History from Family Reconstitution 1580-183\%. Cambridge: Cambridge University Press, 1997. 


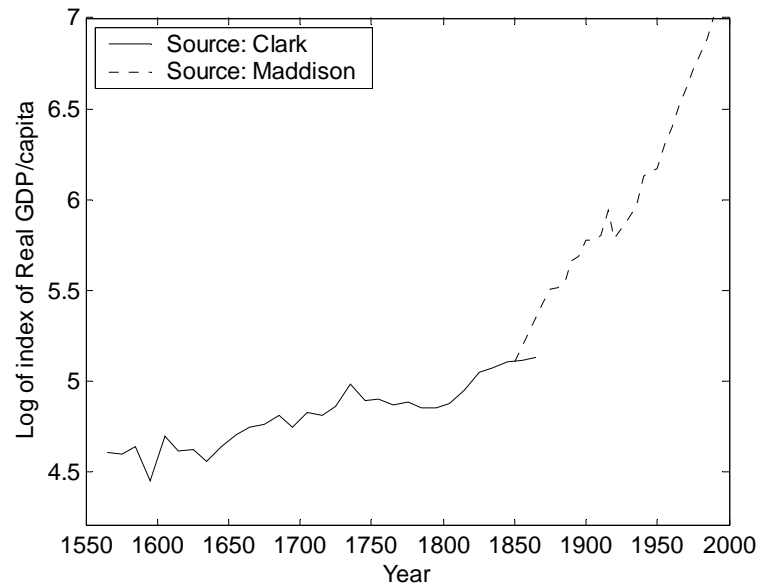

Figure 1. Log of the Real GDP/capita Index

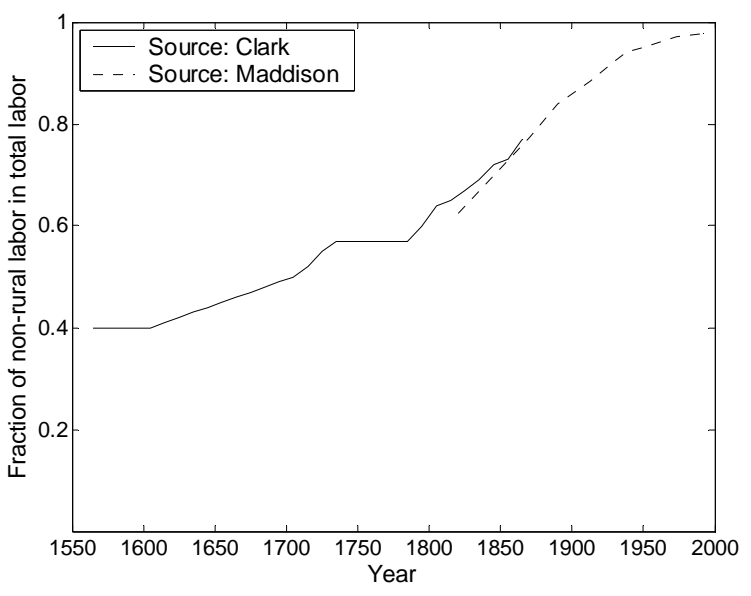

Figure 3. Urbanization

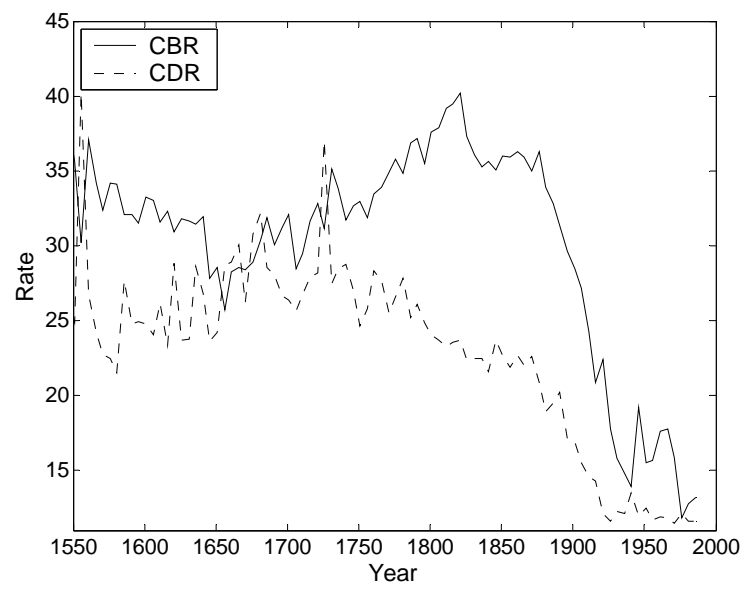

Figure 5. Demographic Transition

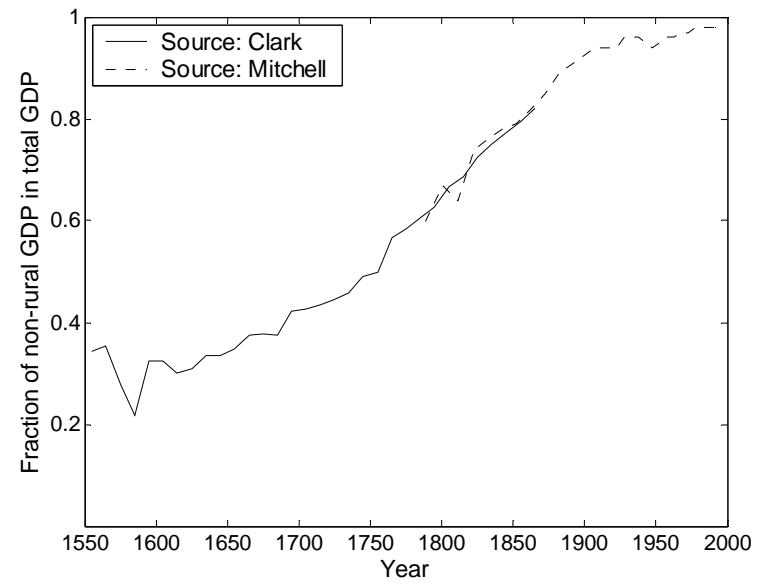

Figure 2. Industrialization

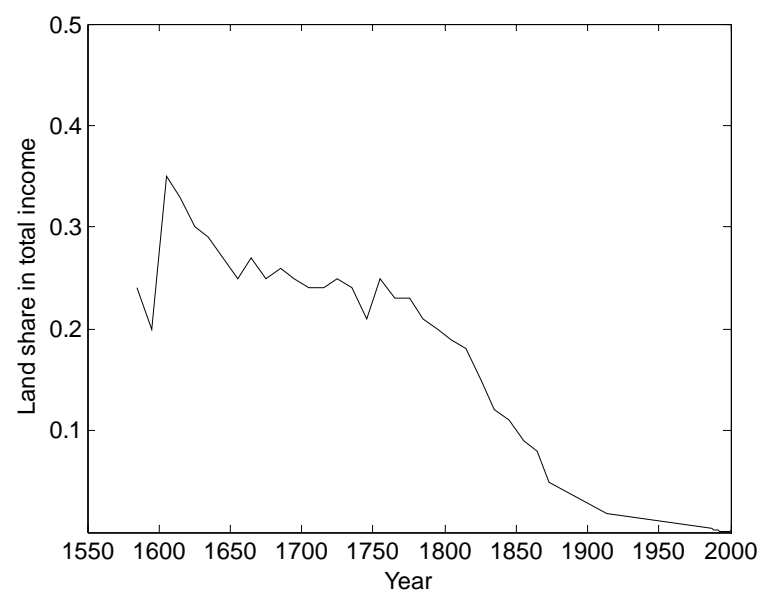

Figure 4. Land Share in Total Income 


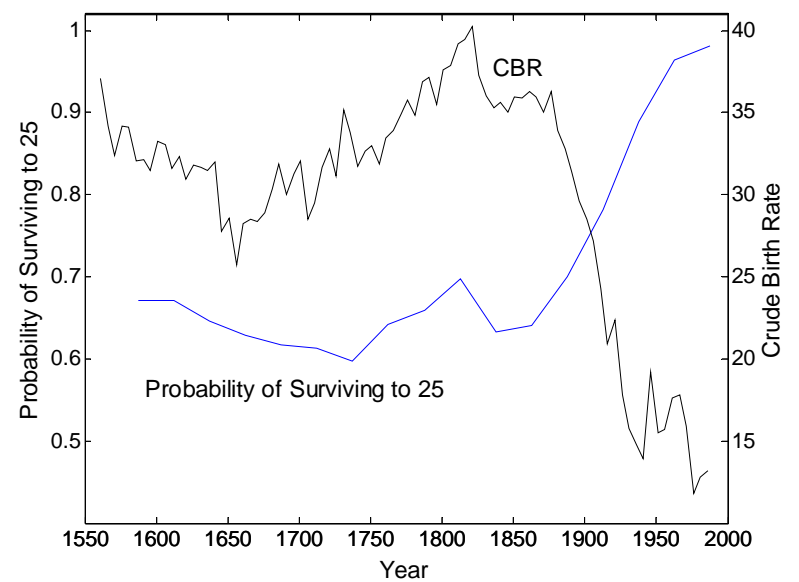

Figure 6. CBR and Young-Age Mortality

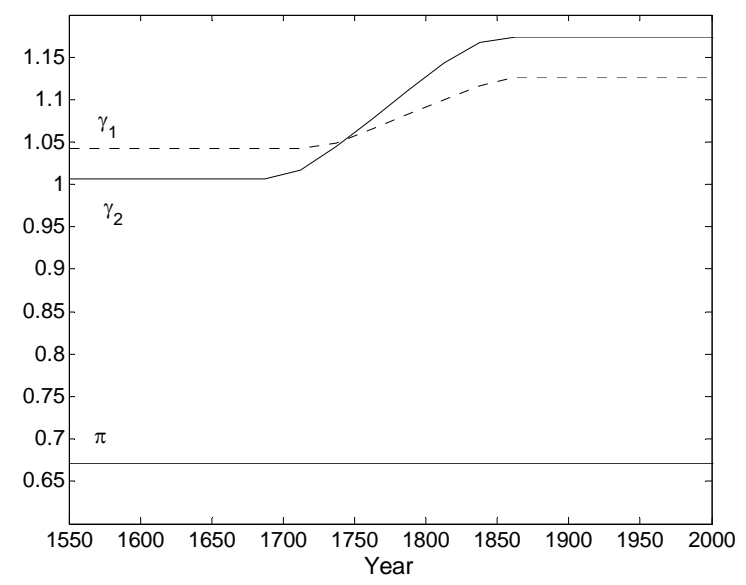

Figure 8. Exp. 1: Changing TFP

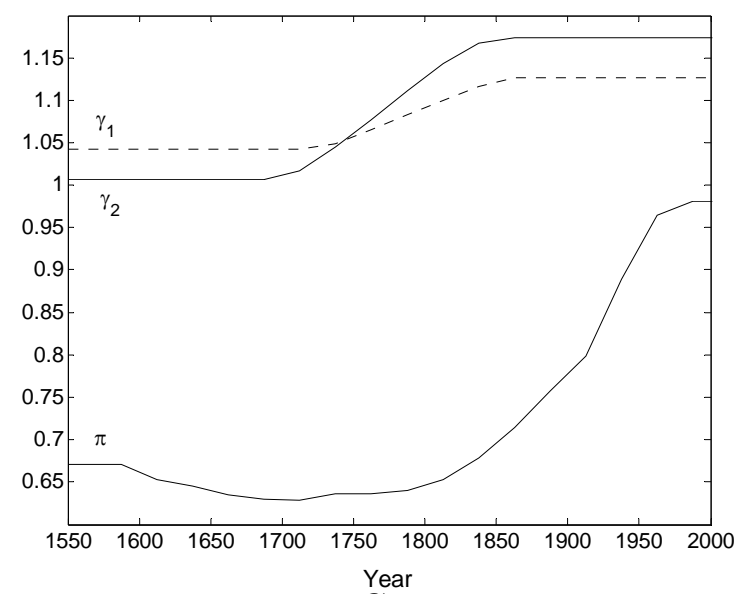

Figure 10. Exp. 3: Changing TFP and $\pi$

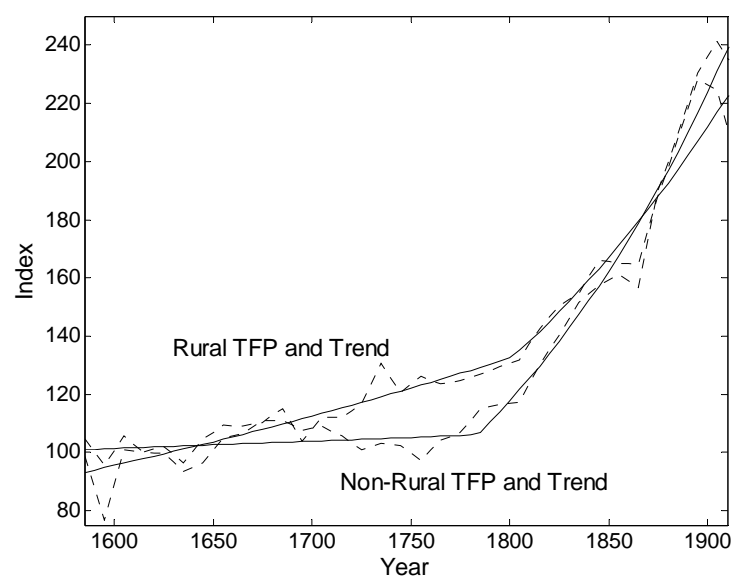

Figure 7. Estimated TFP

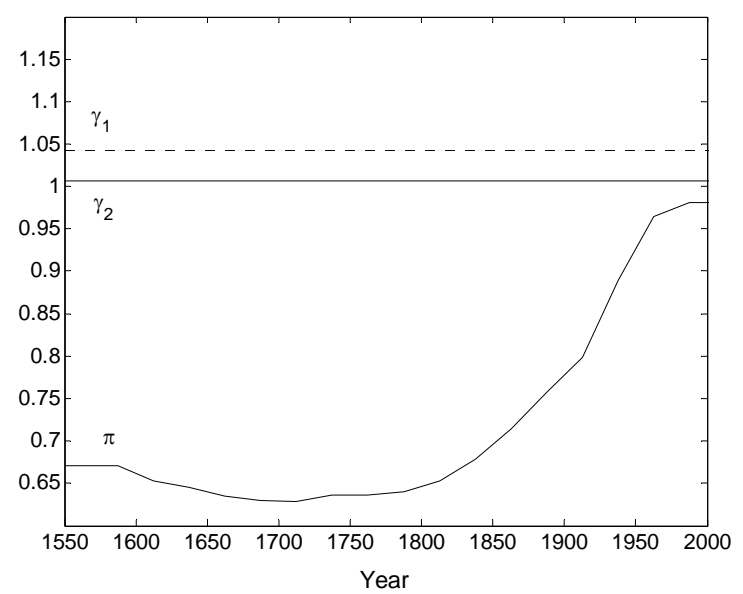

Figure 9. Exp. 2: Changing $\pi$ 


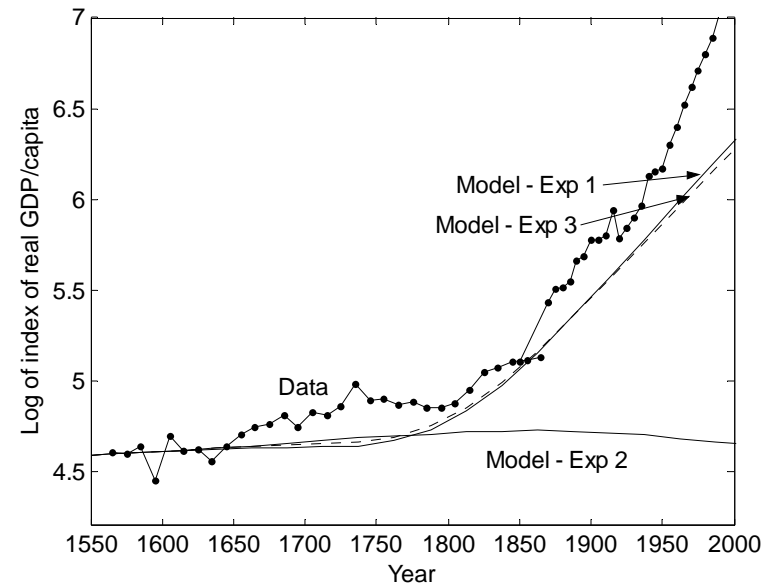

Figure 11. Model vs. Data: Real GDP/capita

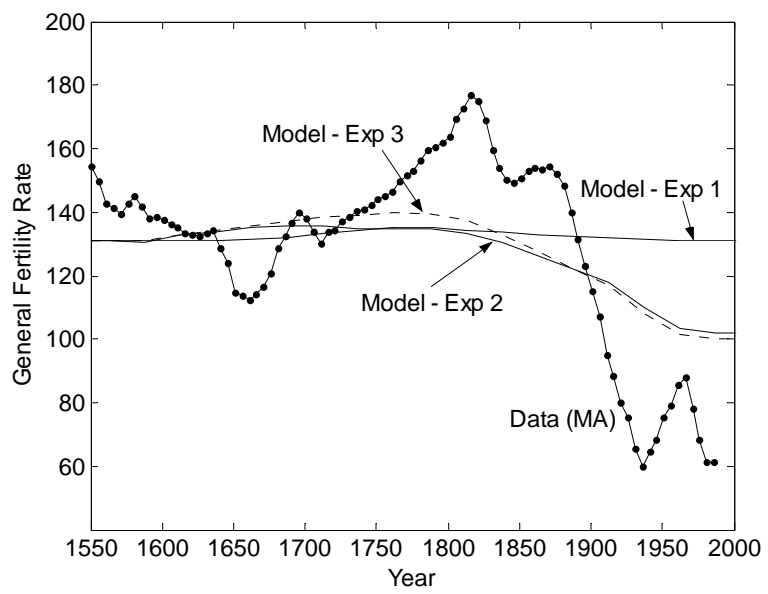

Figure 13. Model vs. Data: GFR

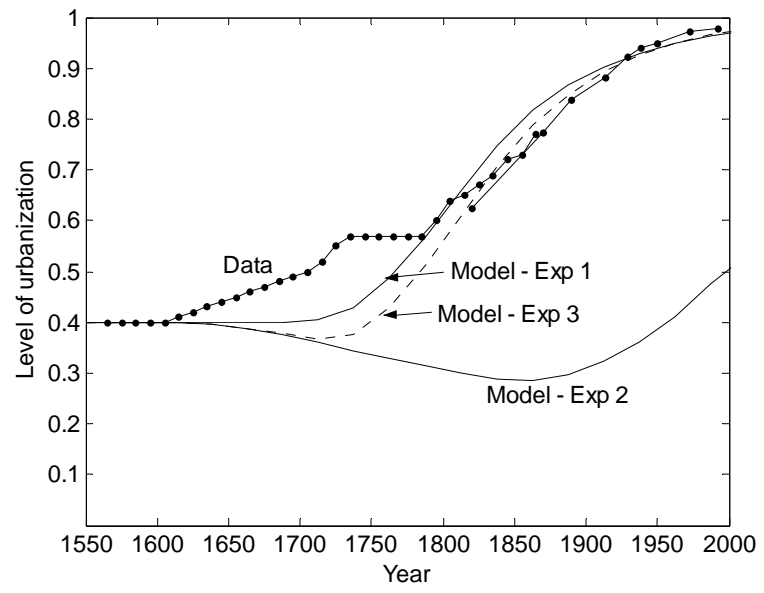

Figure 15. Model vs. Data: Urbanization

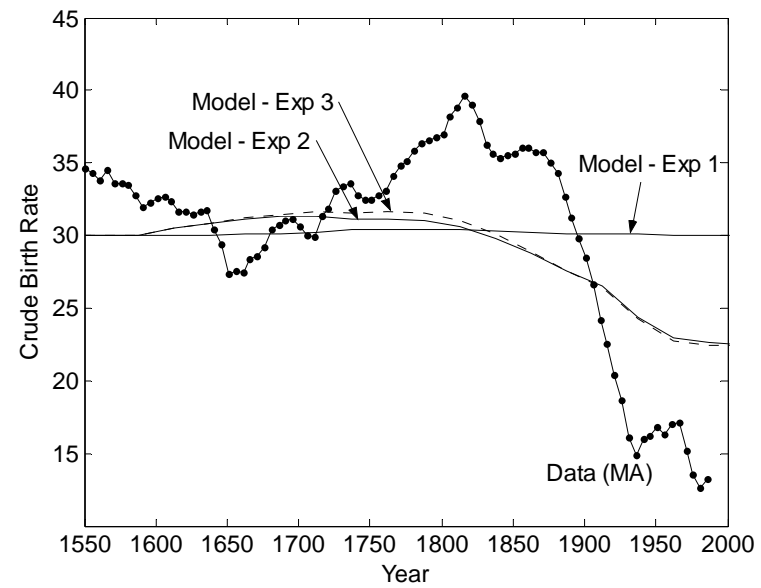

Figure 12. Model vs. Data: CBR

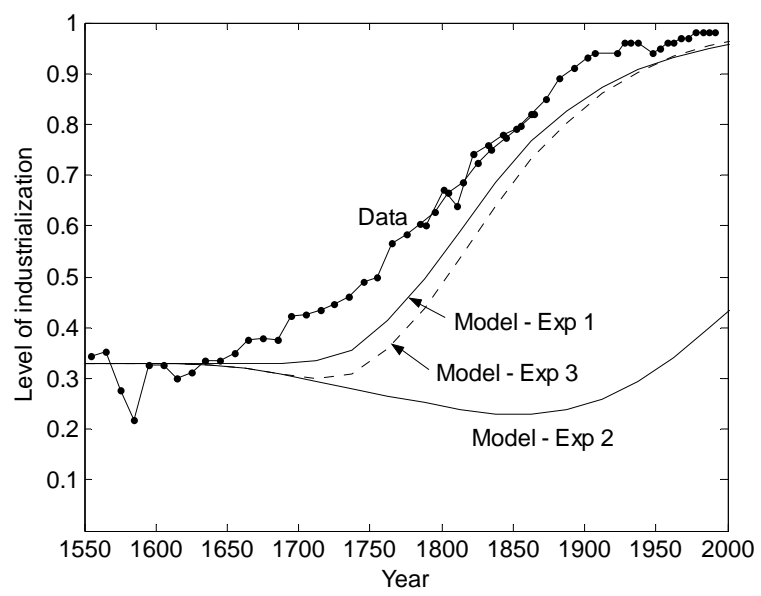

Figure 14. Model vs. Data: Industrialization

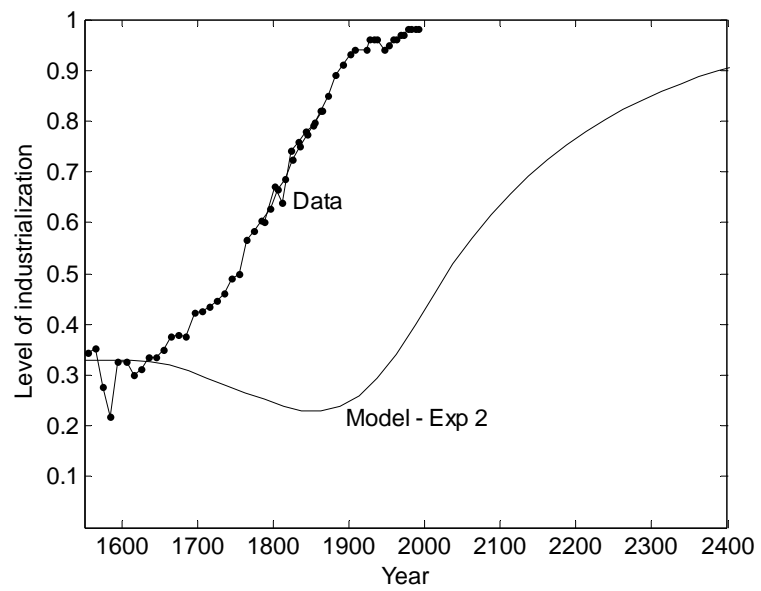

Figure 16. Exp. 2: Industrialization 


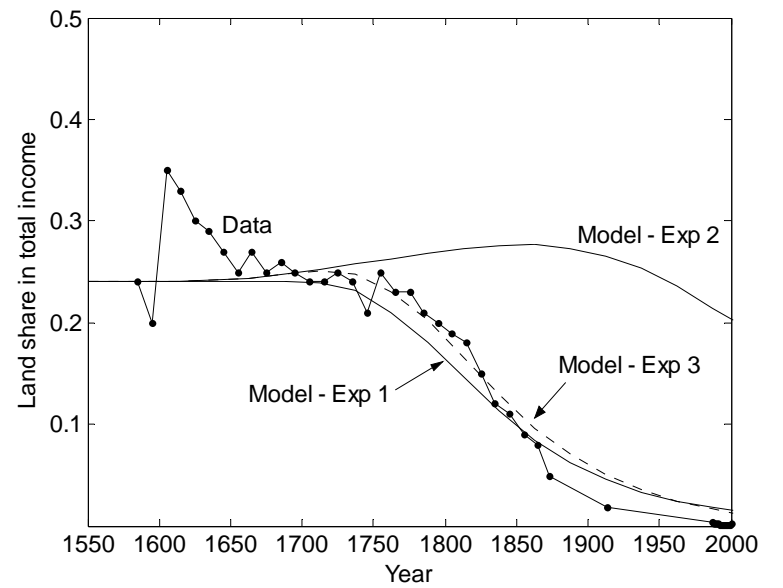

Figure 17. Model vs. Data: Land Share

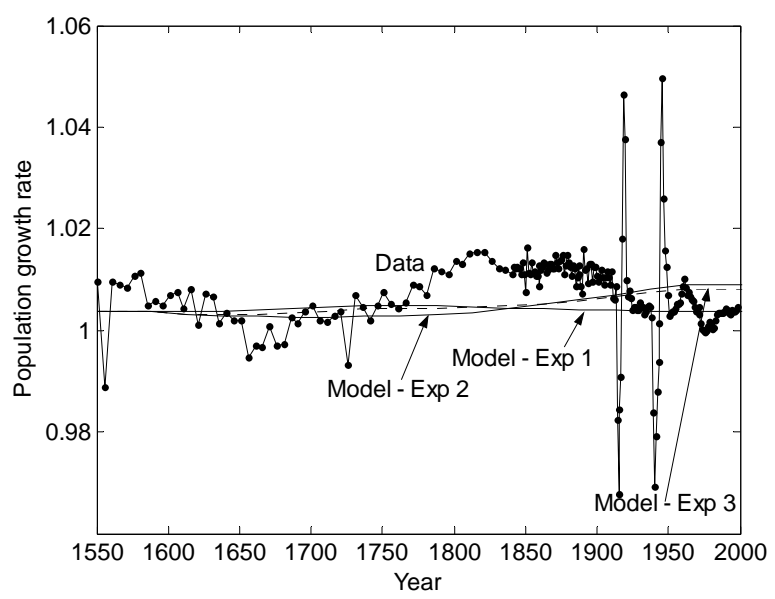

Figure 19. Model vs. Data: Population Growth

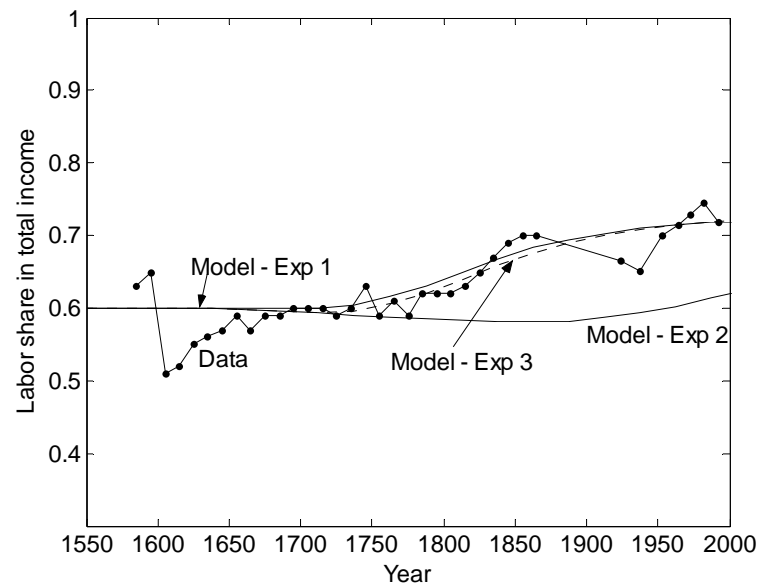

Figure 18. Model vs. Data: Labor Share

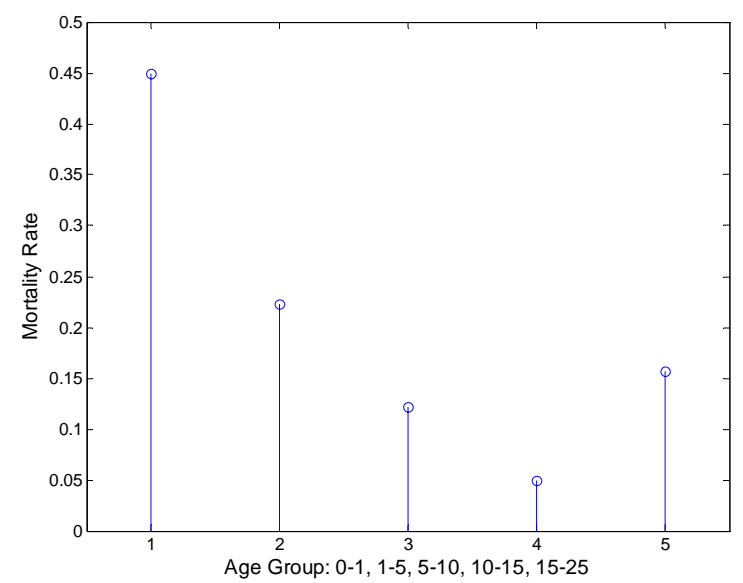

Figure 20. Child Mortality Distribution 